This document is confidential and is proprietary to the American Chemical Society and its authors. Do not copy or disclose without written permission. If you have received this item in error, notify the sender and delete all copies.

\title{
Modulation of Angiogenic Activity by Light-Activatable miRNA-Loaded Nanocarriers
}

\begin{tabular}{|r|l|}
\hline Journal: & ACS Nano \\
\hline Manuscript ID & nn-2017-07538v.R2 \\
\hline Manuscript Type: & Article \\
\hline Date Submitted by the Author: & n/a \\
\hline Complete List of Authors: & $\begin{array}{l}\text { Lino, Miguel; Center for Neurosciences and Cell Biology, University of } \\
\text { Coimbra, } \\
\text { Simões, Susana ; Center for Neuroscience and Cell Biology, University of } \\
\text { Coimbra } \\
\text { Vilaça, Andreia; Center for Neuroscience and Cell Biology, University of } \\
\text { Coimbra } \\
\text { Antunes, Helena; Center for Neuroscience and Cell Biology, University of } \\
\text { Coimbra } \\
\text { Zonari, Alessandra ; Center for Neuroscience and Cell Biology, University of } \\
\text { Coimbra } \\
\text { Ferreira, Lino; Center for Neuroscience and Cell Biology, }\end{array}$ \\
\hline
\end{tabular}




\title{
Modulation of Angiogenic Activity by Light-
}

\section{Activatable miRNA-Loaded Nanocarriers}

\author{
Miguel M. Lino ${ }^{\dagger}$, Susana Simões ${ }^{\dagger}$, Andreia Vilaça ${ }^{\dagger}$, Helena Antunes ${ }^{\dagger+}$, Alessandra Zonari ${ }^{\dagger}$ \\ and Lino Ferreira ${ }^{\dagger *}$
}

${ }^{\dagger}$ Center for Neuroscience and Cell Biology, University of Coimbra, Coimbra, Portugal

${ }^{\ddagger}$ Faculty of Medicine, University of Coimbra, Coimbra, Portugal

KEYWORDS. nanoparticles, microRNA, light-activatable materials, near-infrared, modulation of cell activity

\begin{abstract}
The combinatorial delivery of miRNAs holds great promise to modulate cell activity in the context of angiogenesis. Yet, the delivery of multiple miRNAs with spatiotemporal control remains elusive. Here, we report a plasmonic nanocarrier to control the release of two microRNAs. The nanocarrier consists of gold nanorods (AuNRs) modified with single stranded DNA (ssDNA) for hybridization with complementary DNA-conjugated microRNAs. DNA strands with distinct melting temperatures enable to independently release each microRNA with a near infrared (NIR) laser using the same wavelength but different
\end{abstract}


powers. Tests in human outgrowth endothelial cells (OECs) indicate that this system can be used to silence different targets sequentially and, by doing so, to modulate cell activity with spatio-temporal resolution. Finally, using an in vivo acute wound healing animal model, it is demonstrated that the order by which each miRNA was released in transplanted OECs significantly impacted the wound healing kinetics.

Ischemic diseases are a leading cause of morbidity and mortality in the contemporary world. Several pre-clinical and clinical trials are exploring the therapeutic effect of cell-based therapies, including endothelial progenitor cells (EPCs), in ischemic diseases. ${ }^{1-3}$ Outgrowth endothelial cells (OECs), a sub-population of EPCs, ${ }^{4}$ are of particular interest for the treatment of ischemic diseases ${ }^{5-6}$ and for tissue engineering applications, ${ }^{7}$ given their contribution to the vascularization of tissues and tissue constructs. It is well recognized that the poor survival and engraftment of transplanted cells hinders their clinical efficacy and thus, the development of strategies to modulate the activity of these cells (e.g. survival, proliferation) is paramount to enhance their therapeutic effect. In this setting, the transplantation of cells transfected with modulators that are externally activated at specific times during cell engraftment can be seen as a promising strategy.

MicroRNAs (miRNAs) are non-coding single-stranded RNAs that function as endogenous post-transcription regulators of gene expression and have the ability to affect several biological processes, including differentiation, cell proliferation and survival. ${ }^{8}$ Previous studies have demonstrated that miRNAs are powerful modulators of angiogenesis, ${ }^{9}$ that may act cooperatively to regulate angiogenic factors such as VEGF. ${ }^{10}$ The hypothesis of this work is that the intracellular delivery of two miRNAs (miR-302a-3p and miR-155-5p, hereafter designed as miR-302a and miR-155, respectively) may regulate either cell 
proliferation or survival depending on their temporal delivery. It has been reported that miR$302 \mathrm{a}$ is able to promote cell proliferation by the inhibition of cell cycle regulators expression, such as cyclin D1, which favors the transition in cell cycle from G1 to S phase. ${ }^{11}$ On the other hand, miR-155 regulates endothelial cell survival in hypoxic conditions because increases the level of the pro-survival enzyme, heme-oxygenase. ${ }^{12-13}$ To control the intracellular delivery of miRNAs we have developed a nanocarrier that is triggerable by near infrared light (NIR). Previous studies have demonstrated the use of these nanocarriers for the spatio-temporal delivery of single microRNAs ${ }^{14}$ and siRNAs ${ }^{15-18}$ to modulate cell activity. In those studies, the RNA molecules were encapsulated in nanocarriers ${ }^{14}$ or immobilized on the surface of the nanocarrier by electrostatic interactions ${ }^{17,} 19$ or hybridization ${ }^{16,18}$ with complementary oligonucleotides. The release was induced by the photodisassembly of the NP, ${ }^{14}$ thermal dehybridization of the RNA molecules, ${ }^{16}$ thermal dissociation from a polycationic linker, ${ }^{15}$ or the cleavage of the linker containing the RNA from the nanoparticle surface. ${ }^{17}$ However, so far, no light-responsive formulation has shown the precise control over the release of more than one miRNA.

In this study, we developed a platform for the intracellular delivery of two miRNAs that combines high nanocarrier uptake, efficient endolysomal escape and rapid delivery of each miRNA by varying the power of a single pulse laser. The plasmonic gold nanocarrier (AuNRs) was modified with different single stranded DNA (ssDNA) that act as linkers to immobilize miRNAs on the gold surface through hybridization of complementary strands (Figure 1). The chemistry and the density of the ssDNA linkers were optimized to have sequences with specific melting temperatures and distinct release profiles after activation by a unique NIR laser source. Upon excitation at $780 \mathrm{~nm}$, a photothermal effect induces dehybridization of complementary strands. ${ }^{19}$ To enhance the uptake of the nanocarriers and destabilize the endolysomal membranes during the intracellular uptake we have used a 
peptide with membrane-perturbing abilities, ${ }^{20}$ cecropin mellitin $(\mathrm{CM})$. This peptide has been shown to be non-cytotoxic for several types of cells (e.g. endothelial cells, fibroblasts, macrophages) in concentrations below $5 \mu \mathrm{M} \cdot{ }^{21-22}$ Moreover, melittin peptide derivatives have been used successfully for the intracellular delivery of siRNA or plasmid DNA due to their membrane destabilizing properties. ${ }^{23-24}$ A reporter cell line (HEK-293T) responsive to miR155 and miR-302a has been used to facilitate the monitoring of miRNA release induced by laser irradiation and thus to validate miRNA activity. The cells carry a vector that encodes for mCherry and EGFP. MCherry gene is conjugated with the target of miR-155 and EGFP gene is conjugated with the target of miR-302a. Consequently, transfection with miR-155 leads to exclusive knockdown of mCherry and miR-302a leads to exclusive knockdown of EGFP. ${ }^{25}$ Finally, we demonstrated the biological activity of the sequential release of both miRNAs in OECs derived from human cord blood CD $34^{+}$cells. We further demonstrated that, depending on the sequence of delivery of each miRNA in OECs transplanted in an in vivo wound healing model, it was possible to increase the therapeutic potential of these cells ultimately improving the wound healing rate.

\section{RESULTS AND DISCUSSION}

Synthesis of AuNRs and conjugation with miRNAS. AuNRs synthesized according to the seed mediated method, ${ }^{26}$ and then stabilized with mercaptohexanoic acid (MHA), were coated with ssDNA containing a thiol terminal group at the $5^{\prime}$ end to facilitate the covalent attachment to the AuNR surface (Figure 1). The AuNRs used in this work had an average length of $47 \pm 0.4 \mathrm{~nm}$ and width of $14 \pm 0.2 \mathrm{~nm}$ and showed a plasmon resonance band at 780 $\mathrm{nm}$ regardless of the presence of the miRNA (Figures $2 \mathrm{a}$ and $2 \mathrm{c}$ ). The two ssDNA tested in this work had a poly-thymine spacer (12 or 15 thymines) followed by an oligonucleotide sequence of 15 or 13 bases, respectively (Table S1). The poly-thymine spacer was used to 
keep the oligonucleotide hybridization sequence distant from the AuNR surface. ${ }^{27}$ The number of ssDNA per AuNR was on average $480 \pm 20$, with a coupling efficiency of ssDNA to AuNR of nearly $60 \%$. To immobilize microRNAs on AuNRs, miR-155 and miR-302a modified with a terminal amine group were reacted with the succinimidyl ester of sulfoGMBS and then with ssDNA containing a terminal thiol group (Figure 1a).

a

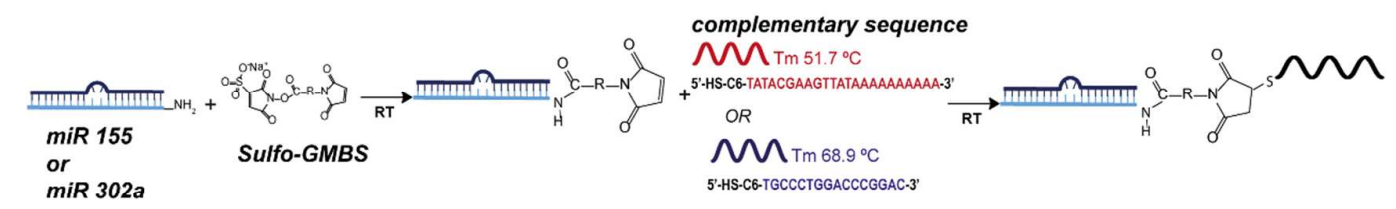

b

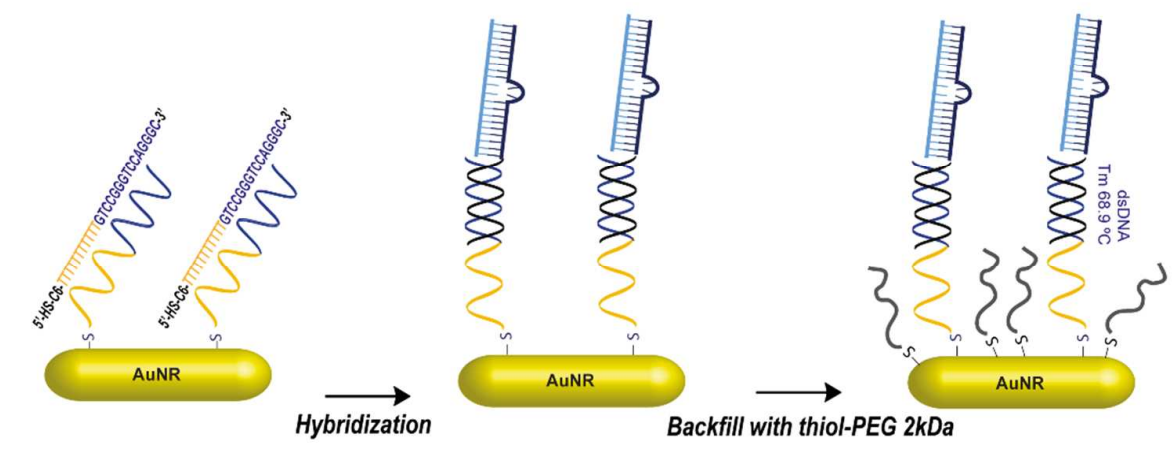

Figure 1. Preparation of miR-dsDNA-AuNR conjugates. (a) Preparation of miR-ssDNA conjugates. miR-155 or miR302a were initially reacted with a heterofunctional linker (SulfoGMBS) by its terminal succinimide ester. The miR conjugate was then reacted with a ssDNA modified with a terminal thiol group (HS-ssDNA). After reaction, the miR-ssDNA conjugate (miR155-ssDNA 51.7 or miR302a-ssDNA 68.9 ) was purified by HPLC. (b) Preparation of AuNR-ssDNA. AuNRs were reacted with HS-ssDNA complementary to the strands of miR155-ssDNA or miR302a-ssDNA conjugates. ssDNA-miR conjugates were then bound to the ssDNA-AuNR by hybridization. The surface of AuNR was then filled with 2 KDa thiolPEG. Upon NIR irradiation, there is an increase in the temperature at the AuNR leading to the DNA de-hybridization and the release of miRs with different kinetics. The release kinetic 
depends on the heat generated (which depends on the power of NIR laser used) and the melting temperature of the oligonucleotides.

To prevent miRNA loss of activity due to conjugation with a ssDNA, each miRNA was conjugated with ssDNA through the sense strand, guaranteeing the structural integrity of the antisense strand, in particular the 5 ' terminus, which is important for initiating the RNA interference mechanism. ${ }^{28}$ The conjugation efficiency, i.e., the percentage of miRNA conjugated with thiolated ssDNA, was $39 \%$ for miR-155 and $22 \%$ for miR-302a (Figure S1). The activity of each miRNA was monitored before and after conjugation with ssDNA, using lipofectamine RNAimax as transfection agent in a reporter cell line responsive to both miRNAs. In the concentration range tested $(0.05$ to $5 \mathrm{nM})$, the fluorescence of the reporter cell line decreases according to the concentration of miRNA used (Figure S2). Both miRNAs are active after conjugation with ssDNA, although miR-302a-ssDNA conjugate is slightly less active than miR-302a at the lowest concentrations tested (0.05-0.5 nM) (Figure S2).

To hybridize ssDNA-miR conjugates to ssDNA-AuNRs, the conjugates were incubated in large excess with ssDNA-AuNRs (400 or 800 -molar fold ratio) at $37^{\circ} \mathrm{C}$ leading to the immobilization of 202 (400-molar fold ratio) and 390 (800-molar fold ratio) ssDNAmiR-155 conjugates per AuNR or 226 and 404 ssDNA-miR-302a per AuNR (Figure 2d). Therefore, the hybridization efficiency of ssDNA-miR conjugates to ssDNA-AuNRs was between 48.8 and 56.5\%. For subsequent experiments, we have used AuNRs with ca. 400 ssDNA-miR conjugates because this number was large enough to elicit a biological response (see below). Our results show that hybridization of the ssDNA-miRNA conjugate does not cause significant changes in the absorbance spectrum of the AuNRs (Figure 2c). In addition, the size of the nanocarrier was not substantially different from the non-conjugated one (Figure 2b). 
a.1

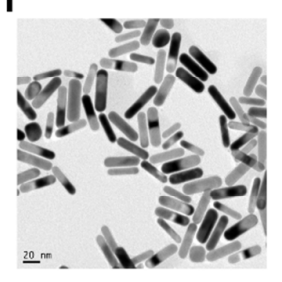

b. 1

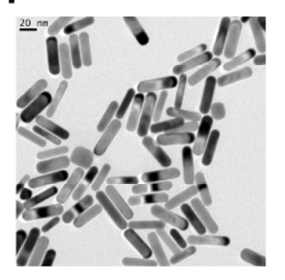

a. 2

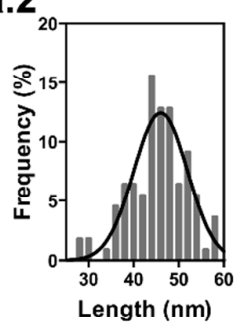

b. 2

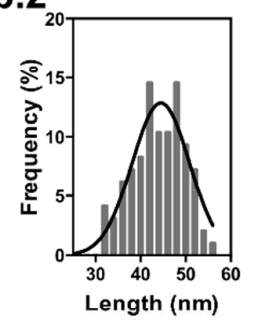

c

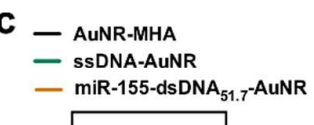

a. 3

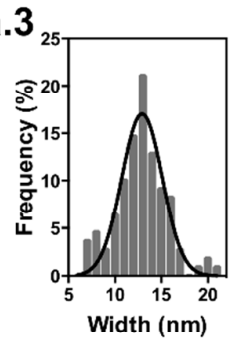

b. 3

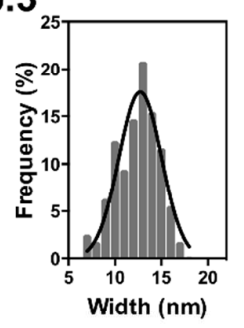

a.4

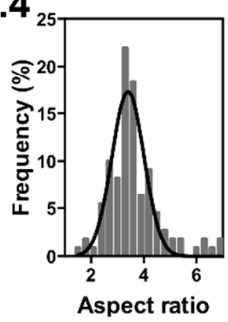

b. 4

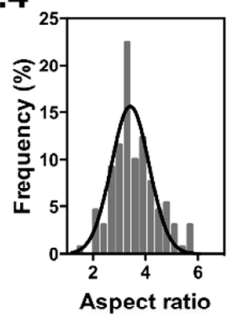

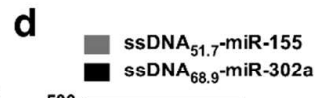

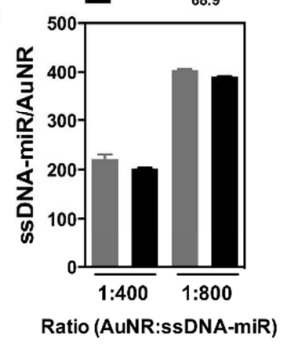

Figure 2. Characterization of AuNRs. Representative TEM images of AuNRs (a.1) and miR-155-dsDNA 51.7 -AuNRs (b.1). AuNR length (a.2 and b.2) and width (a.3 and b.3) and aspect ratio (a.4 and b.4) distribution obtained from TEM images. The AuNRs showed an average length of $47 \pm 0.4 \mathrm{~nm}$, an average width of $14 \pm 0.2 \mathrm{~nm}$ and an aspect ratio of $3.4 \pm$ 0.07. Results are Average \pm SEM $(n=100)$. (c) Absorbance spectra of AuNRs after conjugation with mercaptohexanoic acid (AuNR-MHA), after conjugation with ssDNA s1.7 $_{7}$ (ssDNA $51.7-A u N R s)$ and after hybridization with miR-155-ssDNA (miR-155-dsDNA $51.7^{-}$ AuNR). Surface plasmon resonance band does not change during surface modification. (d) Number of miR-155-ssDNA 51.7 and miR302a-ssDNA 68.9 conjugates hybridized on AuNRs modified with an average of 475 strands per AuNR. The number of miR-ssDNAs hybridized on AuNRs was determined indirectly in the supernatant using SyBr Gold fluorescent dye. Results are Average $\pm \operatorname{SEM}(\mathrm{n}=3)$. 
Light-triggered release of miRNAs from AuNRs. To study the release profiles of miRNAs, we have used AuNRs hybridized with: (i) miR-155 conjugated with ssDNA with a melting temperature of $51.7{ }^{\circ} \mathrm{C}$ (miR-155-ssDNA ${ }_{51.7}$ ) and (ii) miR-302a conjugated with ssDNA with a melting temperature of $68.9{ }^{\circ} \mathrm{C}$ (miR-302a-ssDNA 68.9 ) (Figure 1). Each suspension of miR-dsDNA-AuNR was irradiated for 2 or 5 min and immediately centrifuged. Our results show that miR-155 was released at $1.25 \mathrm{Wcm}^{-2}$ while miR-302a was largely released at $2 \mathrm{Wcm}^{-2}$ (Figures $3 \mathrm{a}$ and $3 \mathrm{~b}$ ). The supernatants of each formulation were then complexed for 20 min with lipofectamine RNAimax and added to HEK-293T cells for $4 \mathrm{~h}$ (Figure $3 \mathrm{a}$ ). The concentration of miR-155-ssDNA ${ }_{51.7}$ released with a laser stimulus of 1.25 $\mathrm{W} \mathrm{cm}^{-2}$ for 2 min was able to inhibit mCherry fluorescence by $80 \%$ compared with the control (Figures $3 \mathrm{c}$ and $3 \mathrm{~d}$ ). Increasing the time or the power of the laser did not decrease significantly mCherry fluorescence when compared to 2 min laser stimulus at $1.25 \mathrm{Wcm}^{-2}$. In contrast, the concentration of miR-302a released with a laser stimulus for 2 or 5 min at 1.25 $\mathrm{Wcm}^{-2}$ did not induce a significant decrease in EGFP fluorescence $48 \mathrm{~h}$ after transfection (Figures 3e and 3f). Yet, the increase of laser power from $1.25 \mathrm{Wcm}^{-2}$ to $2 \mathrm{Wcm}^{-2}$ for $2 \mathrm{~min}$ led to almost $40 \%$ decrease in EGFP fluorescence signal. Overall, our results showed that NIR laser-induced release of miR-ssDNA conjugates correlates with the power of the laser and the melting temperature of the DNA strands, i.e. miR conjugated with higher melting temperature ssDNA $\left(68.9^{\circ} \mathrm{C}\right)$ required a higher laser power to be released from the AuNR surface. 
a

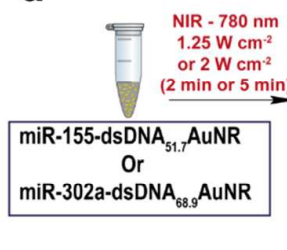

C Hoechst
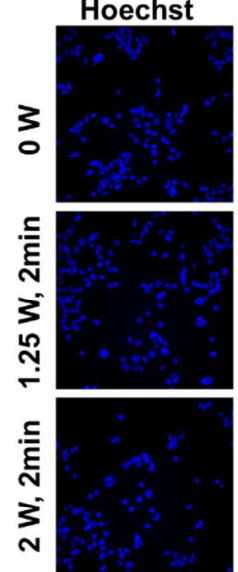

e
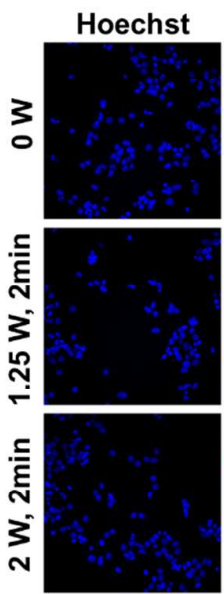

miR-155-ssDNA
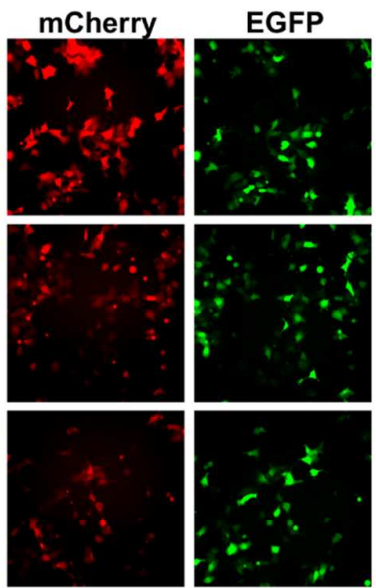

miR-302a-ssDNA
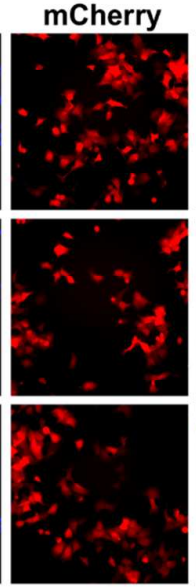
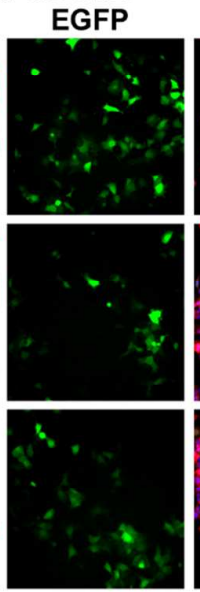

Merge
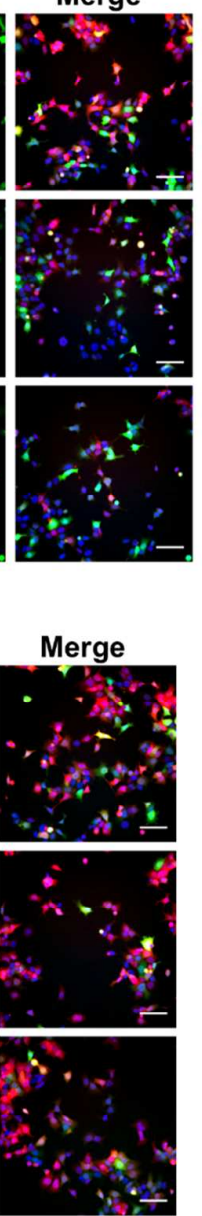

b

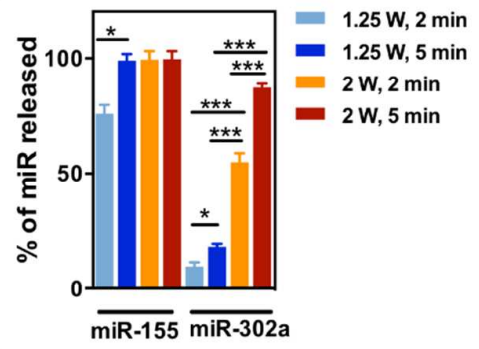

d

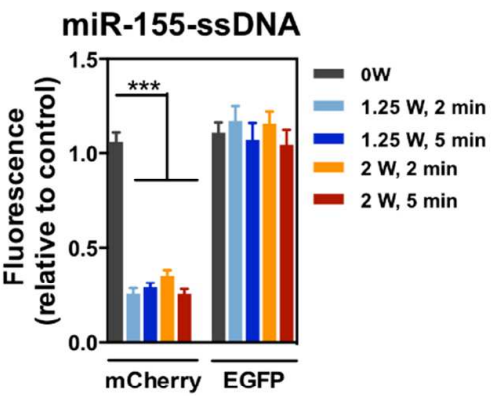

f

miR-302a-ssDNA

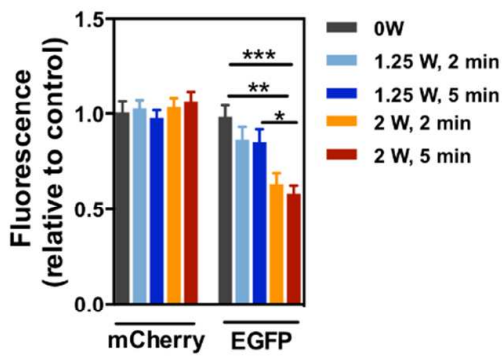

Figure 3. EGFP and mCherry knockdown in HEK-293T after laser induced release of miRNAs. (a) Schematic representation of the experimental protocol. Suspensions of miR155-dsDNA ${ }_{51.7}$-AuNR and miR-302a-dsDNA 68.9 -AuNR were exposed to different laser stimuli at $1.25 \mathrm{Wcm}^{-2}$ (2 and $\left.5 \mathrm{~min}\right)$ and at $2 \mathrm{Wcm}^{-2}$ (2 and $\left.5 \mathrm{~min}\right)$. Immediately after irradiation, suspensions were centrifuged and the supernatants were complexed with Lipofectamine RNAimax and incubated with HEK-293T. (b) Percentage of miR-ssDNA 
released from AuNR with laser irradiation. After irradiation, AuNR suspensions were centrifuged and the amount of miR-ssDNA in the supernatant was determined using $\mathrm{SyBr}$ Gold fluorescent dye. (c and e) Fluorescence microscopy images of HEK-293T exposed to miR-155-ssDNA/RNAimax or miR-302a-ssDNA/RNAimax complexes for $4 \mathrm{~h}$. After $48 \mathrm{~h}$ of incubation, mCherry and EGFP fluorescence were monitored by a high content fluorescence microscope. Scale bar corresponds to $50 \mu \mathrm{m}$. (d and f) mCherry and EGFP fluorescence normalized to the control (supernatant of non-irradiated miR-dsDNA-AuNRs). Results are expressed as Average $\pm \operatorname{SEM}(\mathrm{n}=3$, with 6 microscope fields per sample). In $\mathrm{b}$, $\mathrm{d}$ and $\mathrm{f}, *, * *$ and $* * *$ denote statistical significance $(\mathrm{p}<0.05, \mathrm{p}<0.01$ and $\mathrm{p}<0.001)$ assessed by one-way ANOVA test followed by a Tukey's post-hoc test.

Uptake and endosomal escape of AuNRs. miRNA interference mechanism requires the delivery of miRNA in the cell cytoplasm. ${ }^{8}$ To enhance cell uptake and endosomal escape of miR155-dsDNA $51.7-$ AuNRs we have used $\mathrm{CM}$, a cell penetrating peptide. $\mathrm{CM}$ is a cationic amphiphilic peptide with membrane-perturbing capacity, ${ }^{29}$ leading to endosomal escape of membrane-impermeable molecules. ${ }^{30}$ The effect of $\mathrm{CM}$ in the uptake and intracellular localization of miR155-dsDNA 1.7 -AuNRs labelled with TRITC was studied using confocal microscopy and transmission electron microscopy (TEM) (Figure 4). Cells were incubated with miR155-dsDNA 51.7 -AuNR-TRITC $(50 \mu \mathrm{g} / \mathrm{mL})$ for $4 \mathrm{~h}$ in DMEM (without FBS), washed and finally characterized by confocal microscopy and inductive coupled plasma mass spectrometry (ICP-MS). Our results showed that increased concentrations of CM led to increased intracellular levels of miR155-dsDNA ${ }_{51.7}$-AuNR-TRITC as measured by confocal microscopy (Figure 4b) and ICP-MS analyses (Figure 4d). Because the uptake of the AuNR formulation begins with an initial adhesion to the cell membrane, followed by the activation 
of an energy-dependent uptake mechanism, we evaluated whether $\mathrm{CM}$ interacted with miR155-dsDNA 51.7 -AuNR before cell interaction (Figure S3). Indeed, the CM interacted with the miR-dsDNA-AuNRs because the zeta potential of the formulation increased after the contact with CM. The positive charge of the miR-dsDNA-AuNRs: CM complex may facilitate the interaction with the negatively-charged regions of the cell membrane. In addition, it is possible that the hydrophobic regions of the peptide further facilitated the interaction with cell membrane as previously demonstrated with model cell membranes. ${ }^{31}$

The effect of $\mathrm{CM}$ in the endolysosomal escape was also characterized. The colocalization of miR155-dsDNA 51.7 -AuNR-TRITC with Lysotracker was lower in the presence of $\mathrm{CM}$ than in the absence of peptide showing that the peptide contributes for the endolysosomal escape of the nanocarrier (Figure 4c). However, increasing the concentration of the peptide from $5 \mu \mathrm{M}$ to $10 \mu \mathrm{M}$ did not decrease the coefficient of colocalization (Figure 4c). Furthermore, our results suggest a cumulative effect of $\mathrm{CM}$ and laser irradiation in the endosomal escape of the miR155-dsDNA 51.7 -AuNR-TRITC likely due to the fact that the peptide destabilizes the endosomal membrane allowing the escape of part of the nanocarriers. As confirmed by TEM (Figures 4e, 4f and 4g), the NIR laser also promotes the escape of AuNRs that were still inside the endosomes, probably via a photochemical process through generation of radical species. ${ }^{32}$ 


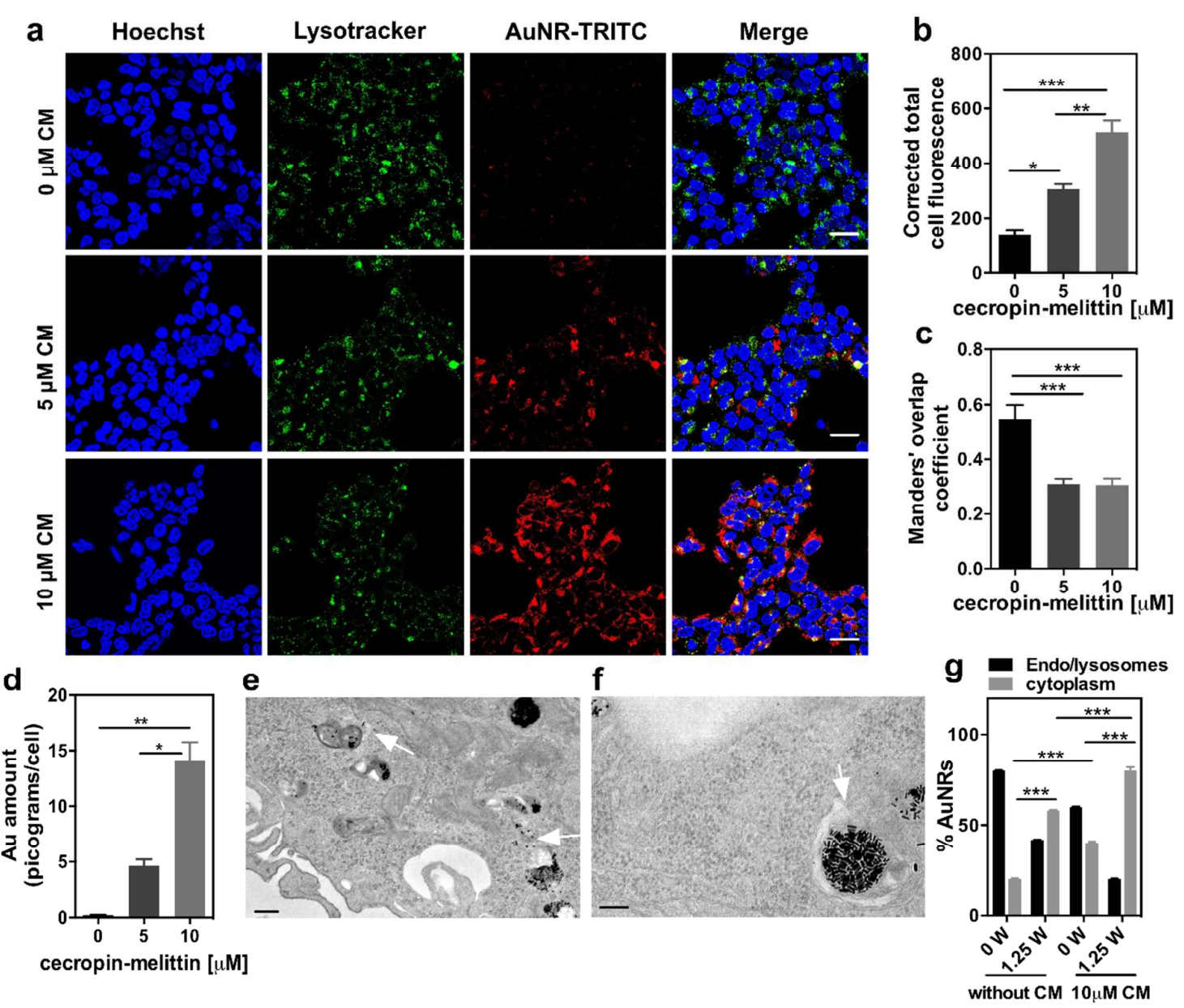

Figure 4. Uptake and intracellular localization of miR-dsDNA-AuNR in HEK-293T

cells. (a) Confocal images of HEK-293T cells stained with LysoTracker green after $4 \mathrm{~h}$ incubation with miR-155-dsDNA ${ }_{51.7}$-AuNR-TRITC and CM. Scale bar is $30 \mu \mathrm{m}$. (b) Intensity of the signal of AuNR-TRITC per cell. (c) Colocalization between AuNR-TRITC and lysotracker green expressed as Manders' overlap coefficient assessed by ImageJ analysis. (d) Amount of Au per cell quantified by ICP-MS. (e) TEM image of HEK-293T incubated with miR-155-dsDNA 51.7 -AuNR before laser activation. White arrows indicate the presence of AuNRs in the cytoplasm. Scale bar corresponds to $500 \mathrm{~nm}$. (f) TEM image of HEK-293T incubated with miR-155-dsDNA $51.7-$ AuNR after laser activation. White arrow indicates the site of rupture of the endosomal membrane. Scale bar corresponds to $200 \mathrm{~nm}$. (g) Percentage of AuNRs present in the cytoplasm and vesicles (endosomes and lysosomes). Quantification 
results from the analysis of 30 images/condition. In b, c, d and g, results are expressed as Average $\pm \operatorname{SEM}(\mathrm{n}=3) . * * *$ and $* * *$ denote statistical significance $(\mathrm{p}<0.05, \mathrm{p}<0.01$ and $\mathrm{p}<0.001$ ) assessed by one-way ANOVA followed by Tukey's post-hoc test.

To evaluate the cytotoxicity of miR-dsDNA-AuNR co-incubated with CM and NIR laser radiation (up to $2 \mathrm{Wcm}^{-2}$ ), reporter cells were exposed for $4 \mathrm{~h}$ to the nanocarrier (miR155-dsDNA $51.7-$ AuNR was used as a model), washed, activated or not with a NIR laser for 2 min and finally incubated for $24 \mathrm{~h}$ upon which cell viability was assessed. Our results showed no statistically significant differences between the conditions tested indicating that the treatment was well tolerated by the HEK-293T cells (Figure S4a). The toxicity of AuNRs and $\mathrm{CM}$ was also evaluated in OECs (Figure S4b). Here, CM was cytotoxic in OECs at concentration $10 \mu \mathrm{M}$. These results are in line with previous results collected by us indicating that $\mathrm{CM}$ has a higher cytotoxicity against ECs than other cell types. ${ }^{33}$ Therefore, for subsequent assays with OECs, a concentration of $5 \mu \mathrm{M}$ of $\mathrm{CM}$ was used. Importantly, the irradiation of AuNRs in both type of cells had no incremental cytotoxicity to the one observed for AuNRs without irradiation (Figures S4a and S4b).

Overall, our results indicated that the efficient uptake and endosomal escape of AuNRs conjugated with miRNAs required the use of a cell penetrating peptide. Given the cellular toxicity of soluble CM, future clinical applications of CM-mediated intracellular delivery of AuNRs might require the chemical immobilization of the CM to the surface of the nanocarrier. This methodology has been used successfully by us to decrease the toxicity of $\mathrm{CM}$ in human cells. ${ }^{33-34}$ Another finding of our study is that the irradiation (laser power up to $2 \mathrm{Wcm}^{-2}$ ) of AuNRs within cells has no significant biological impact. It is known that the irradiation of AuNRs with CW lasers leads to a local increase of temperature at the AuNR surface, which decreases with the distance as $1 / r$, where $r$ is defined as the distance from the 
center of the AuNR. ${ }^{35}$ This means that the temperature of the bulk is significantly lower than the temperature in the vicinity of the AuNR. Thus, it is possible to achieve in the vicinity of the AuNR, temperatures that are close to the melting temperatures of the DNA strands immobilized on the AuNR surface, without inducing deleterious effects to cells.

\section{Light-triggered release of miRNAs from AuNRs within a reporter cell line. To}

test the laser-induced release of miR-ssDNA conjugates in cells, HEK-293T cells were incubated for $4 \mathrm{~h}$ with miR155-dsDNA $51.7-\mathrm{AuNR}$ or miR302a-dsDNA $68.9-\mathrm{AuNR}(50 \mu \mathrm{g} \mathrm{mL}$ ${ }^{1}$ ) in the presence of $\mathrm{CM}$ and subsequently irradiated for 2 min with different laser powers $\left(1.25\right.$ or $\left.2 \mathrm{Wcm}^{-2}\right)$. Cells incubated with miR155-dsDNA $51.7-\mathrm{AuNR}$ and activated with laser stimuli of $1.25 \mathrm{Wcm}^{-2}$ or $2 \mathrm{Wcm}^{-2}$ showed a $50 \%$ reduction in mCherry fluorescence after 48 $\mathrm{h}$ (Figure S5c). In contrast, for cells incubated with miR302a-dsDNA 68.9 -AuNR, a statistically significant reduction in EGFP fluorescence was only observed for a laser stimulus of $2 \mathrm{Wcm}^{-2}$ (Figure S5d).

For the sequential release of miR-155 and miR-302a, cells were incubated with miR155-dsDNA $51.7-\operatorname{AuNR}\left(25 \mu \mathrm{g} \mathrm{mL}^{-1}\right)$ and miR302a-dsDNA 68.9 -AuNR $\left(25 \mu \mathrm{g} \mathrm{mL}^{-1}\right)$ for 4 h. In these conditions, the intracellular amount of miR155 and miR302a was similar as evaluated by qRT-PCR (Figure S6). After incubation, cells were irradiated for 2 min at 1.25 $\mathrm{Wcm}^{-2}$ and a second stimulus $\left(2 \mathrm{~min}, 2 \mathrm{Wcm}^{-2}\right)$ was applied $2 \mathrm{~h}$ after the first stimulus (Figure 5a). MiR-155, which was conjugated to the oligonucleotide with low melting temperature $\left(\operatorname{Tm} 51.7{ }^{\circ} \mathrm{C}\right)$, was preferentially released by the first stimulus $\left(1.25 \mathrm{Wcm}^{-2}, 2\right.$ min) yielding a $42 \%$ decrease in mCherry fluorescence (Figure $5 \mathrm{c}$ ). On the other hand, miR302a which was conjugated to the oligonucleotide with high melting temperature (Tm 68.9 ${ }^{\circ} \mathrm{C}$ ), was preferentially released by the second stimulus $\left(2 \mathrm{Wcm}^{-2}, 2 \mathrm{~min}\right)$ yielding a $41 \%$ decrease in EGFP fluorescence (Figure 5c). 
a miR-155-dsDNA-AuNR miR-302a-dsDNA-AuNR

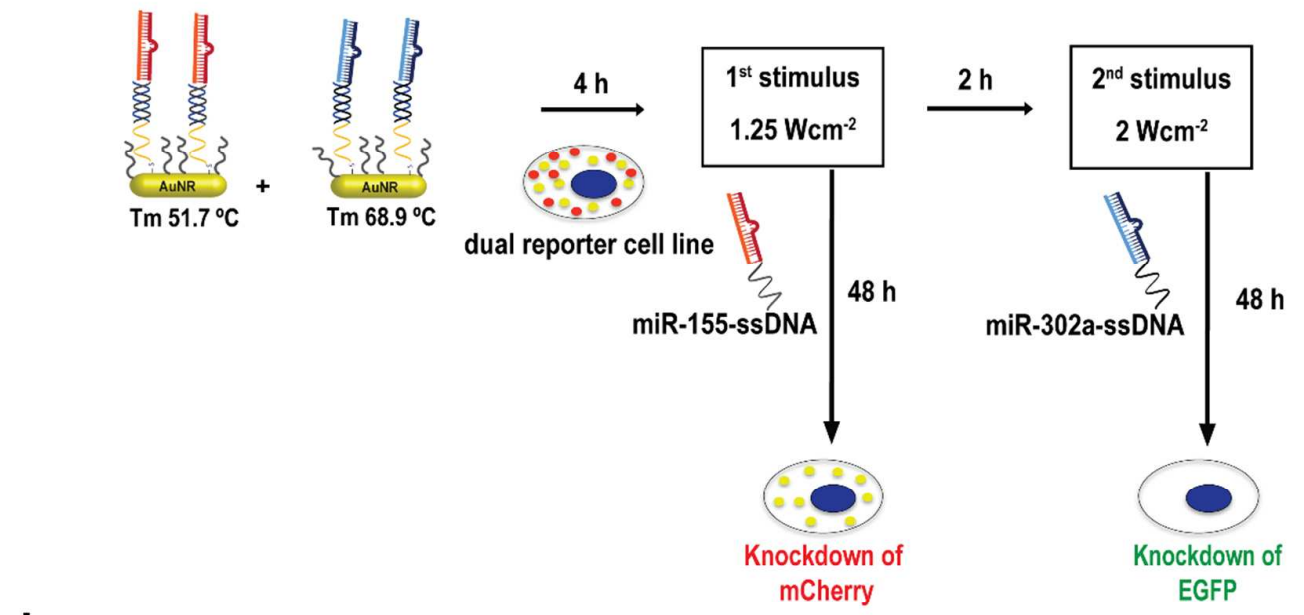

b

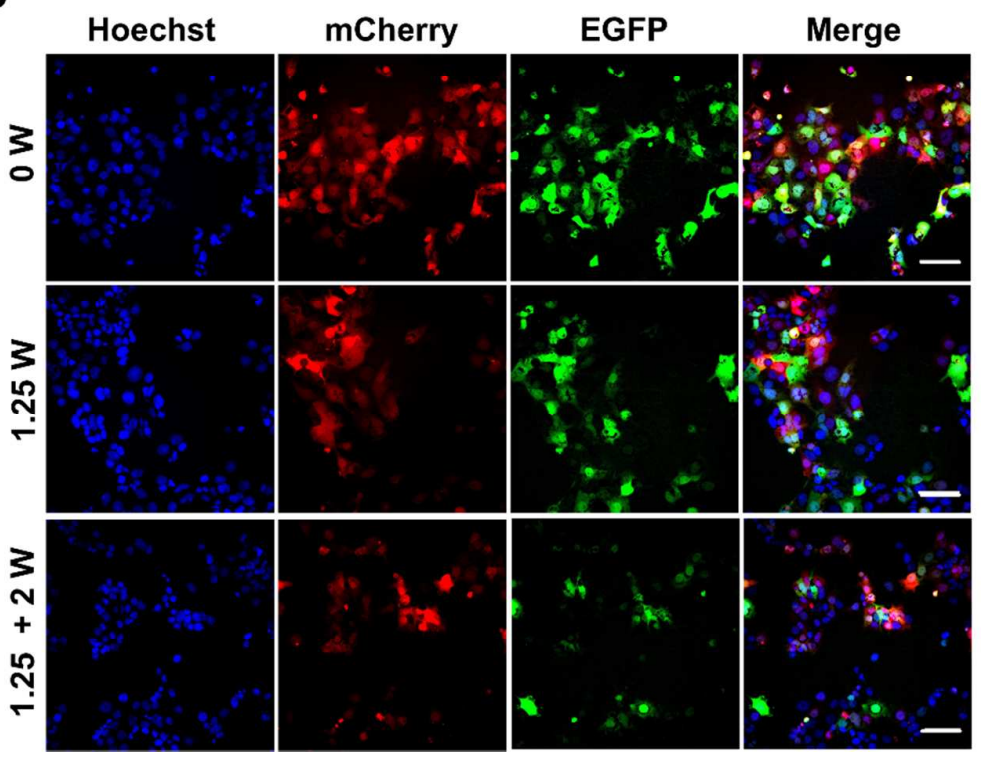

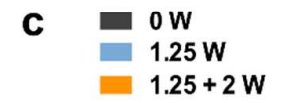

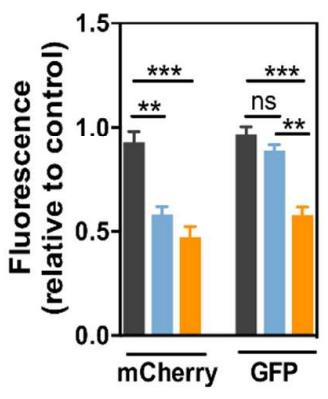

Figure 5. Sequential delivery of miRNAs in HEK-293T. (a) Schematic representation of the protocol used. HEK-293T were incubated with a mixture of miR155-dsDNA $51.7-\mathrm{AuNR}$ and miR302a-dsDNA 68.9 -AuNR for $4 \mathrm{~h}$. After incubation cells were exposed to one laser stimulus $\left(2 \mathrm{~min}\right.$ at $\left.1.25 \mathrm{Wcm}^{-2}\right)$ or two laser stimuli $\left(2 \mathrm{~min}\right.$ at $1.25 \mathrm{Wcm}^{-2}$ and $2 \mathrm{~min}$ at 2 $\mathrm{Wcm}^{-2}$ ) with an interval of $2 \mathrm{~h}$ between the stimuli. (b) Fluorescence microscopy images of cells incubated with miR-dsDNA-AuNRs for $4 \mathrm{~h}$ in the presence of CM. Scale bar corresponds to $50 \mu \mathrm{m}$. (c) Quantification of cell fluorescence $48 \mathrm{~h}$ after laser irradiation. 
Results are expressed as average $\pm \operatorname{SEM}(n=3$, with 6 microscope fields per sample). *** denotes statistical significance $(\mathrm{p}<0.001)$ assessed by one-way ANOVA followed by Tukey's post-hoc test.

Overall, our results demonstrated the possibility of temporal delivery of 2 miRNAs conjugated with AuNRs within cells. Moreover, our results further demonstrated that the intracellular delivery of the miRNA was dependent in the oligonucleotide sequence and power of the laser.

In vitro light-triggered modulation of endothelial cell activity. To test the potential of this delivery system in the modulation of cell activity we incubated OECs with miR155$\mathrm{dsDNA}_{51.7}$-AuNR and miR302a-dsDNA $68.9-\mathrm{AuNR}\left(50 \mu \mathrm{g} \mathrm{mL}^{-1}\right)$ and cell response to each miRNA was evaluated in terms of proliferation and survival in hypoxia culture conditions (Figure 6a). The impact of each miRNA was first evaluated in transfection assays with lipofectamine (Figure S7a). MiR-155 did not promote proliferation, but was able to increase survival, whereas miR-302a promoted cell proliferation but did not have a positive impact in survival (Figures S7b and S7c). Interestingly, the combined effect of both miRNAs induced proliferation and increased survival to a level that was equivalent to the effect of vascular endothelial growth factor (VEGF) (Figure S7d and S7e). Our results using OECs transfected with miR-dsDNA-AuNRs showed a statistically significant increase (6.7 fold) in survival with the first stimulus ( $2 \mathrm{~min}$ at $1.25 \mathrm{Wcm}^{-2}$ ) (Figure 6b) which was indicative of lightinduced release of miR-155. With the second stimulus $\left(2 \mathrm{~min}\right.$ at $\left.2 \mathrm{Wcm}^{-2}\right)$, OECs showed a statistical significant increase in proliferation which was indicative of light-induced release of miR-302a (Figure 6c). Interestingly, the sequential delivery of miRNAs had a higher impact in cell survival than simultaneous delivery of both miRNAs (Figure S8). 
The impact of each miRNA on gene expression was also evaluated (Figure S9). As expected, OEC transfection with miR-155 led to up-regulation of heme-oxygenase (HMOX1) gene transcripts, ${ }^{12}$ which in turn led to a higher cell survival in hypoxic conditions, as demonstrated previously. ${ }^{13}$ In addition, OECs transfection with miR-302a led to an increase in the number of Cyclin D (CCND1) gene transcripts, which is required for cell cycle progression, particularly for the transition G1 to S phase. ${ }^{11,36}$ Moreover, transfection of OECs with miR-302a caused an increase in MCM4 gene transcripts, which encodes the mini chromosome maintenance complex component 4, a DNA helicase that is essential for the initiation of DNA replication and has been reported as a marker for cell proliferation. ${ }^{37}$ These results are in agreement with the functional impact of each miRNA in terms of survival and proliferation of OECs.

Overall, our results demonstrated the possibility to modulate the activity (i.e. survival and proliferation) of endothelial cells after transfection with miRNAs-conjugated AuNRs. The cell activity was observed after the light-triggered release of each miRNA. Our results further show that the sequential delivery of miRNAs had a higher pro-survival effect than the simultaneous delivery of both miRNAs. This might be explained by the synergistic effect between pro-survival genes that are activated initially by miR-155 with pro-proliferation genes that are activated by the miR-302a. Further studies are necessary to identify the genes that are involved in the synergetic effects. Importantly, cells treated by the sequential delivery of miR-155 and miR-302a had a 1.6-fold increase in cell survival (this corresponds to $\sim 31 \%$ of cell survival) as compared to non-treated cells. It is possible that other schemes of delivery, either by changing the order of miRNA release (i.e., miR-302a followed by the release of miR-155) or the time between each stimulus might improve even more the survival of the cells. 
a miR-155-dsDNA-AuNR miR-302a-dsDNA-AuNR
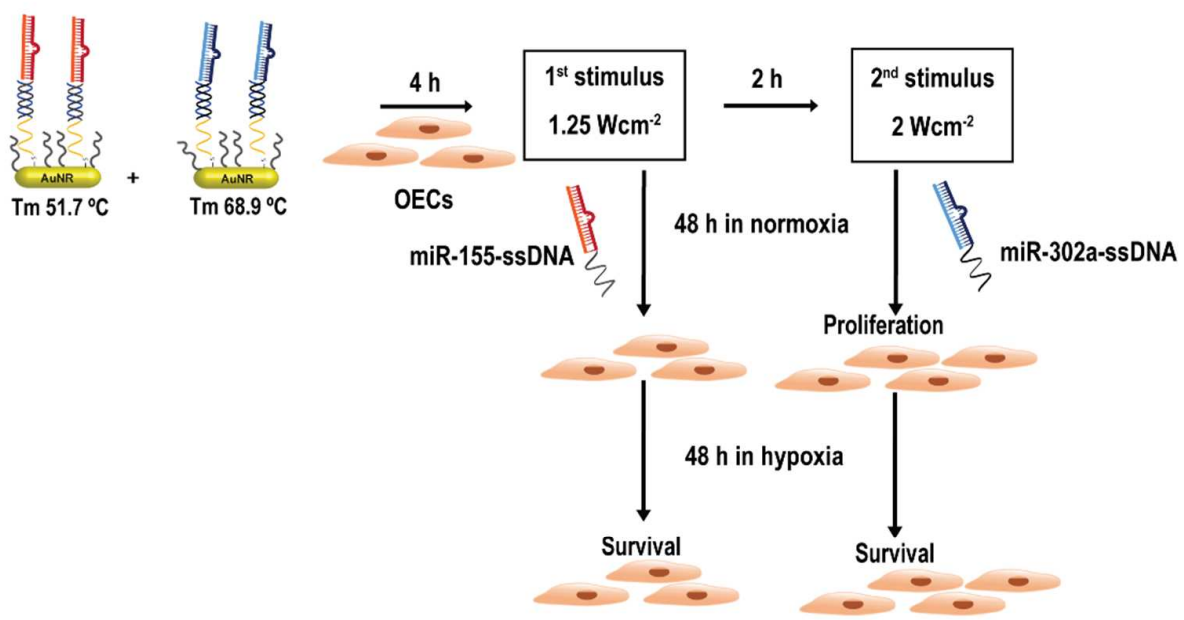

b

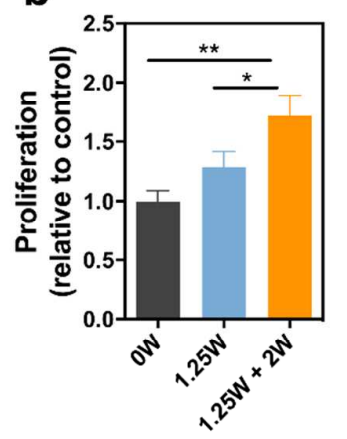

C

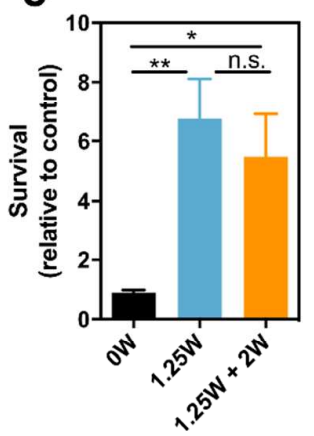

Figure 6. Sequential delivery of miRNAs in OECs. (a) Schematic representation of the protocol. OECs were incubated for $4 \mathrm{~h}$ with a mixture of miR155-dsDNA 51.7 -AuNR and

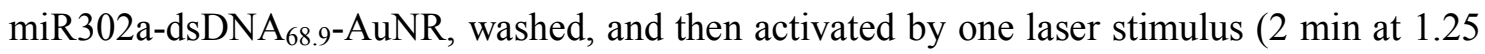
$\left.\mathrm{Wcm}^{-2}\right)$ or two laser stimuli $\left(2 \mathrm{~min} 1.25 \mathrm{Wcm}^{-2}\right.$ and 2 min at $\left.2 \mathrm{Wcm}^{-2}\right)$ with an interval of $2 \mathrm{~h}$ between each stimulus. Cells were then incubated in normoxia conditions for $48 \mathrm{~h}$ followed by cell nuclei quantification. Afterwards, cells were incubated in hypoxia conditions for $48 \mathrm{~h}$ followed by cell nuclei quantification. Survival was determined as the ratio between the final (after hypoxia) and the initial number (after hypoxia) of cells. (b) Cell proliferation. (c) Cell survival. In $b$ and $c$, results are expressed as average $\pm \operatorname{SEM}(n=5) . *$ and $* *$ denote statistical significance $(\mathrm{p}<0.05$ and $\mathrm{p}<0.01)$ assessed by one-way ANOVA followed by Tukey's post- 
hoc test. Cell proliferation and survival were normalized by cells transfected with ssDNAAuNRs.

Modulation of cell activity in an in vivo model of wound healing. Angiogenesis is particularly dependent on the ordered expression of multiple miRNAs that control proliferation, cell survival, migration and mobilisation of cells. ${ }^{38}$ Although some formulations have been developed for delivery of miRNAs to modulate the behaviour of endothelial cells and promote angiogenesis, ${ }^{39-40}$ the synergistic effect of multiple miRNAs has not been fully explored. Moreover, it remains relatively unknown the importance of temporal orchestration in the delivery of multiple miRNAs. Therefore, we investigated the effect of the OECs transfected with miR155-dsDNA-AuNR and miR302a-dsDNA-AuNR and how the control over their temporal release impacts wound healing in an in vivo acute wound healing model (Figure 7a). Transfected OECs were transplanted subcutaneously in mice in the border of the wound and in one sequence (sequence $\mathrm{A}$ ), miR-155 conjugated with ssDNA $_{51.7}$ was released by a first stimulus $\left(2 \mathrm{~min}\right.$ at $1.25 \mathrm{Wcm}^{-2}$ ) and miR-302a conjugated with ssDNA 68.9 was released by a second stimulus $\left(2 \mathrm{~min}\right.$ at $2 \mathrm{Wcm}^{-2}$ ). In another sequence (sequence B), the order of delivery was inverted by changing the DNA strands conjugated to each miRNA. The wound healing kinetics was monitored during 10 days by the quantification of wound area. Our results indicated that OECs transfected with miR302a-dsDNA $51.7-\mathrm{AuNR}$ and miR155dsDNA $_{68.9}$-AuNR in equal concentration and activated by sequence $\mathrm{B}$ enhanced the wound healing kinetics as compared to OECs alone (Figures $7 \mathrm{~b}$ and $7 \mathrm{c}$ ). The effect was statistically significant at days $4-5$, thus in the early phase of the wound healing. Histological analysis indicated the presence of granulation tissue at day 5 post-wounding (Figure $7 d$ ). The engraftment and location of human OECs in mouse skin samples were monitored by confocal microscopy (Figure 7e) in tissues excised at day 5. In both experimental conditions (i.e. 
transplanted cells activated by sequences A or B), human OECs were observed in the vicinity of mouse endothelial cells. A quantitative estimation of cell engraftment was performed by qRT-PCR (Figure 7f). In this case, human DNA in mouse skin samples was determined using a primer sequence specific for human cells (see Supporting Information, Table S2). Our results show that animals transplanted with OECs transfected with miR302a-dsDNA $51.7^{-}$ AuNR and miR155-dsDNA 68.9 -AuNR had the highest cell engraftment and the highest wound healing kinetics. Although it has been demonstrated that the in vitro delivery of miR155 followed by miR-302a had a positive effect on cell survival (Fig. S8), this did not translate into significant results in terms of wound healing kinetics. The complexity of the in vivo environment might play an important role in the final biological output played by the miRNAs. Factors such as oxygen concentration, inflammation and oxidative stress, might play important roles besides the biological effect of the miRNAs. These factors are very difficult to reproduce in vitro. In addition, it is hard to discriminate the effect of cell survival from the effect of cell proliferation in the in vivo results and thus any correlation with the in vitro results is difficult to determine.

Overall, our results indicate that the temporal control in the delivery of more than one miRNA is important for their biological effect. Depending in the signalling pathways activated by each miRNA, the second miRNA might have or not a synergetic effect. To the best of our knowledge, there are only two studies reporting the use of light-triggerable formulations for the delivery of miRNAs in vivo. In one of the studies, the miRNA was modified with a photolabile caging group sensitive to UV-light, ${ }^{41}$ which has a very limited penetration depth in biological tissues and can induce cytotoxicity. ${ }^{42}$ The other study reports a formulation sensitive to NIR light for the delivery of one miRNA. ${ }^{14}$ The present work is the first report on light-controlled sequential release of more than one miRNA using the same light source. 
1

2

3

4

5

6

7

8

9

10

11

12

13

14

15

16

17

18

19

20

21

22

23

24

25

26

27

28

29

30

31

32

33

34

35

36

37

38

39

40

41

42

43

44

45

46

47

48

49

50

51

52

53

54

55

56

57

58

59

60

The current approach may be useful in applications other than topical (skin, eyes, etc...) disorders. Organs such as the gut, brain as well as the urinary system may be accessible using fiber-optic devices that are already used in clinical practice for photodynamic therapy. ${ }^{43}$ Near infrared light has a penetration depth in the order of millimetres to centimetres. ${ }^{44}$ Furthermore, the current delivery platform may be also applied in the treatment of diseases such as cancer in which combinatorial miRNA therapies have been shown to be beneficial. ${ }^{45-47}$ 
a

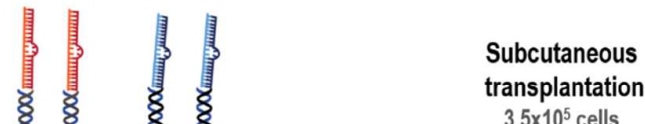
\& 8 o $83.5 \times 10^{5}$ cells

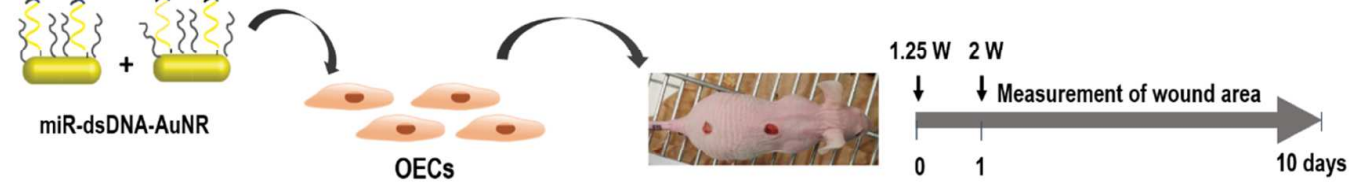

$4 \mathrm{~h}$ incubation

b

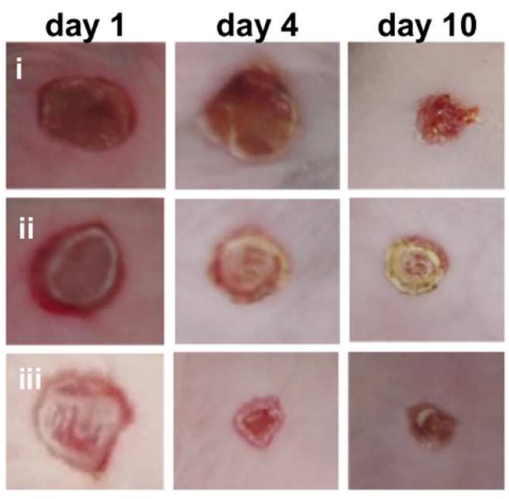

C $\rightarrow$ cells

$\rightarrow$ cells + (miR155-DNA ${ }_{51.7}$-AuNR + miR-302a-DNA 68.9 -AuNR)

- cells + (miR302a-DNA $51.7-$ AuNR + miR-155-DNA 68.9 -AuNR)

d
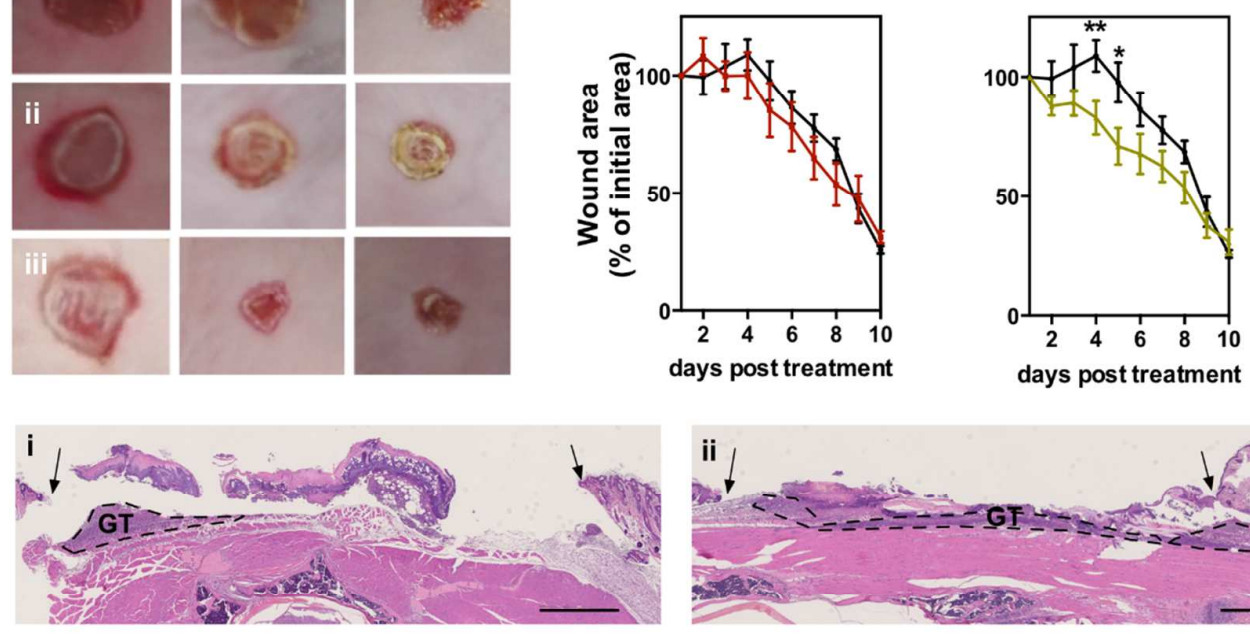

e
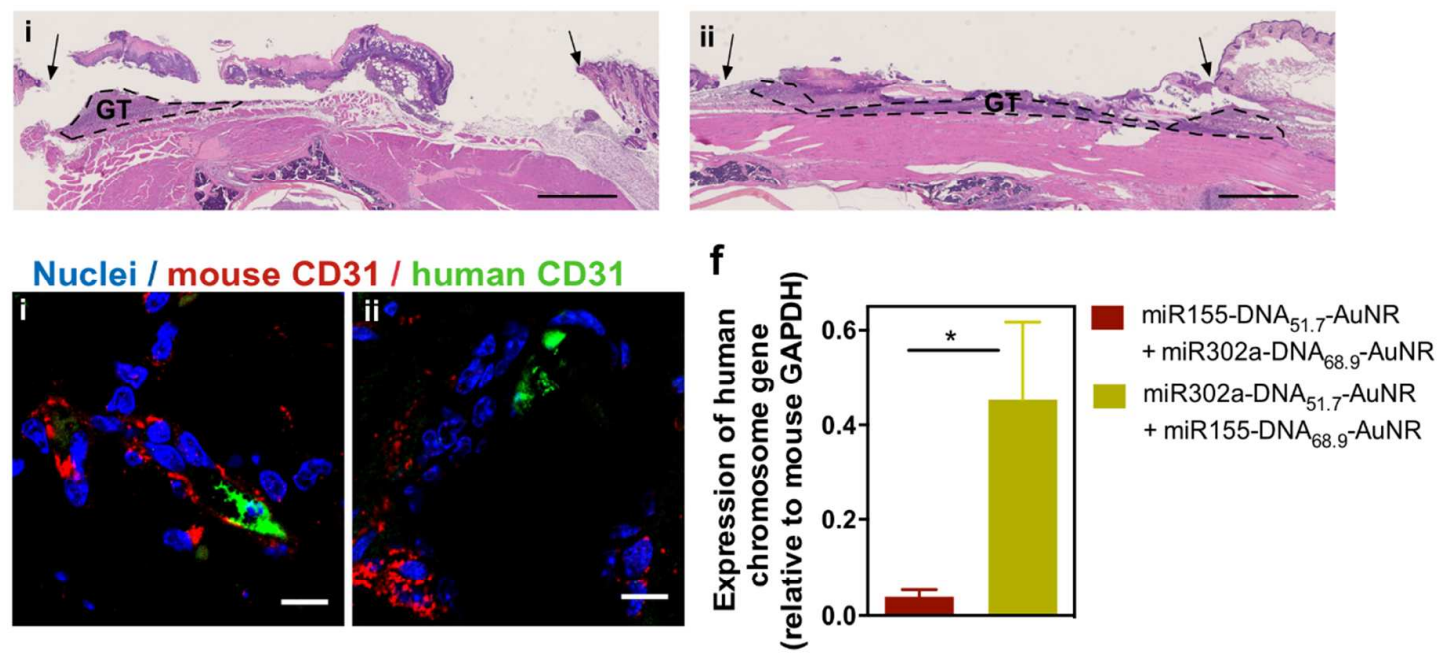

Figure 7. Transplantation of OECs in a mouse model of wound healing. Transplantation of OECs in a mouse model of wound healing. (a) Schematic representation of the protocol. OECs were incubated for $4 \mathrm{~h}$ with a mixture of miR-dsDNA-AuNRs. After incubation, cells were trypsinized and transplanted subcutaneously in dorsal wounds created in nude mice. After transplantation, the site of injection was irradiated for $2 \mathrm{~min}$ at $1.25 \mathrm{Wcm}^{-2}$. After $24 \mathrm{~h}$, a second stimulus was applied $\left(2 \mathrm{~min}\right.$ at $\left.2 \mathrm{Wcm}^{-2}\right)$. (b and c) Wound closure in nude mice 
treated with cells previously incubated or not with miR-dsDNA-AuNR (i - OECs; ii - OECs incubated with miR155-dsDNA $51.7-A u N R$ and miR302a-dsDNA $68.9-A u N R$; iii - OECs incubated with miR302a-dsDNA $51.7-$ AuNR and miR155-dsDNA 68.9 -AuNR). Results are expressed as average $\pm \operatorname{SEM}(\mathrm{n}=7-8) . *$ and $* *$ denote statistical significance $(\mathrm{p}<0.05$ and $\mathrm{p}<0.01$ ) assessed by unpaired t-test. (d) Histological analysis of mouse skin samples excised 5 days post-wounding. Brightfield images of mouse skin stained with hematoxylin/eosin. i OECs incubated with miR155-dsDNA $51.7-\mathrm{AuNR}$ and miR302a-dsDNA 68.9 -AuNR; ii - OECs incubated with miR302a-dsDNA $51.7-\mathrm{AuNR}$ and miR155-dsDNA $68.9-\mathrm{AuNR}_{\text {. Black arrows }}$ indicate the epidermal wound edges. GT is granulation tissue. Scale bar corresponds to 1 mm. (e) Confocal images showing the presence of OECs in vessel-like structures on mouse skin samples excised 5 days post-wounding (i - OECs incubated with miR155-dsDNA $51.7^{-}$ AuNR and miR302a-dsDNA $68.9-A u N R ;$ ii - OECs incubated with miR302a-dsDNA $51.7^{-}$ AuNR and miR155-dsDNA 68.9 -AuNR). Scale bar corresponds to $10 \mu \mathrm{m}$. (f) Quantification by qRT-PCR of human DNA in mouse skin samples excised 5 days post-wounding. Results are expressed as average $\pm \operatorname{SEM}(\mathrm{n}=5)$.

\section{CONCLUSIONS}

In conclusion, we have developed light-responsive NPs, that when combined with an endosomal escape agent, can deliver more than one miRNA. The system works as an optical switch of biological circuits involved in cell proliferation and survival with spatial and temporal control. Although the use of ssDNA has been reported for the immobilization of siRNAs on plasmonic nanocarriers, the ssDNA did not confer a specific release profile to the biomolecule, since the release was obtained through the cleavage of thiol-gold bonds. ${ }^{18}$ Even if the differential release of siRNAs is possible by cell transfection with multiple carriers, the delivery of those biomolecules would require the use of multiple lasers and more importantly, 
it will be difficult to control the stoichiometry between non-coding RNAs. ${ }^{48}$ In the present work, the differential release was modulated by varying the linkers that attach the miRNA to the gold surface and not by changing the size of the nanocarrier, allowing the use of a single wavelength. Our results show that the order in the sequential release of two miRNAs has significant impact in the modulation of endothelial cell activity.

\section{ASSOCIATED CONTENT}

Supporting Information. Supporting Information Available: DNA sequences, purification of DNA-miR conjugates, cytotoxicity studies, transfection experiments and RT-PCR results (Figure S1-S9). This material is available free of charge via the Internet at http://pubs.acs.org

\section{AUTHOR INFORMATION}

\section{Corresponding Author}

*1ino@uc-biotech.pt

The authors declare no competing financial interest.

\section{ACKNOWLEDGMENTS}

The authors would like to thank the financial support of FCT (SFRH/BD/81705/2011 to ML and SFRH/BPD/105327/2014 to SS) and both ERC project ("Nanotrigger", ref: 307384) and ERA Chair project (ERA@UC, ref: 669088) through European Union's Horizon 2020 program and the critical input of Dr. Hugo Fernandes (Faculty of Medicine, University of Coimbra). 


\title{
EXPERIMENTAL SECTION
}

Materials. hsa-miR-155-5p and hsa-miR-302a-3p with a terminal amine group in the passenger strand were purchased from Dharmacon (GE Healthcare). CM (with amino acid sequence: KWKLFKKIGAVLKVLC) was purchased from Caslo Laboratories. Thiolated oligonucleotide strands, hexadecyltrimethylammonium bromide (CTAB), sodium borohydride $\left(\mathrm{NaBH}_{4}\right)$, silver nitrate $\left(\mathrm{AgNO}_{3}\right)$, hexanethiol and mercaptohexanoic acid, and other chemicals were all purchased from Sigma-Aldrich and used as received without further purification. Sodium dodecyl sulfate (SDS) was purchased from VWR. N-[ $\gamma-$ maleimidobutyryloxy] sulfosuccinimide ester (sulfo-GMBS), LysoTracker ${ }^{\circledR}$ Green DND-26, fetal bovine serum (FBS) and trypsin-EDTA solution were purchased from Thermo Fisher Scientific. Dulbecco's Modified Essential Medium (DMEM) is a commercial product of Merck Millipore. Endothelial Growth Cell Medium (EGM-2) was purchased from Lonza. Purified water with resistivity above $18.2 \mathrm{M} \Omega . \mathrm{cm}^{-1}$ was obtained by reverse osmosis (MilliQ, Millipore). Other reagents were analytical grade.

\begin{abstract}
AuNR synthesis. AuNRs were prepared following the seed mediated method. ${ }^{26}$ The seed solution was prepared by the addition of ice-cold sodium borohydride $\left(\mathrm{NaBH}_{4}, 10 \mathrm{mM}, 0.3 \mathrm{~mL}\right)$ to a solution of hexadecyltrimethylammonium bromide (CTAB) $(0.1 \mathrm{M}, 5 \mathrm{~mL})$ containing gold(III) chloride hydrate $(0.25 \mathrm{mM})$. The solution was stirred for 2 min and then kept at $25^{\circ} \mathrm{C}$ for 8 min. The growth solution was prepared by the sequential addition of silver nitrate $\left(\mathrm{AgNO}_{3}, 5 \mathrm{mM}, 3.2\right.$ $\mathrm{mL}), \mathrm{HAuCl}_{4}(50 \mathrm{mM}, 2 \mathrm{~mL})$ and ascorbic acid $(0.1 \mathrm{M} ; 1.5 \mathrm{~mL})$ to a CTAB solution $(0.1 \mathrm{M}, 200$ $\mathrm{mL})$, mixing gently after each step. Finally, the seed solution was added to the growth solution. The growth solution was kept at $28^{\circ} \mathrm{C}$ for $2 \mathrm{~h}$ and then centrifuged at $9000 \mathrm{~g}$ to purify the AuNRs.
\end{abstract}


To facilitate conjugation with ssDNAs, the surfactant on the surface of AuNRs was replaced by mercaptohexanoic acid (MHA), using a method already reported with slight modifications. ${ }^{49}$ First, hexanethiol $(1.5 \mathrm{~mL})$ was added to the AuNR-CTAB suspension (2.5 nM, $1 \mathrm{~mL})$. The AuNRs were transferred to the organic phase by adding acetone $(3 \mathrm{~mL})$ followed by gentle shacking. Then the organic phase was transferred to a new tube to which toluene $(2 \mathrm{~mL})$ and methanol $(5 \mathrm{~mL})$ were added. The solution was centrifuged at $5000 \mathrm{~g}$ for $10 \mathrm{~min}$, and the pellet was resuspended in toluene $(0.5 \mathrm{~mL})$ by brief sonication. The organic to aqueous phase was performed as follows. AuNR-hexanethiol $(1 \mathrm{~mL})$ in toluene was added to mercaptohexanoic acid (MHA, $5 \mathrm{mM})$ in toluene $(9 \mathrm{~mL})$ at $95{ }^{\circ} \mathrm{C}$. The reaction proceeded under reflux with magnetic stirring for $15 \mathrm{~min}$. Modification with MHA caused the formation of AuNR aggregates. After cooling to room temperature, the aggregates were washed twice with toluene by decantation and then with isopropanol to deprotonate the carboxylic groups. Then, AuNR aggregates were resuspended in $1 \times$ TBE. The ligand exchange was confirmed by zeta potential measurements.

Functionalization of AuNR-MHA with single strand DNA (ssDNA). ssDNAs (sequences are in Table S1) carrying a thiol C6 modification were reduced with 100- fold molar excess of Tris(2-carboxyethyl)phosphine (TCEP) for $1 \mathrm{~h}$. The reduced ssDNA $(4 \mu \mathrm{L}, 50 \mu \mathrm{M})$ was added to a AuNR suspension $(0.5 \mathrm{nM} ; 0.5 \mathrm{~mL}$, in $10 \mathrm{mM}$ phosphate buffer $\mathrm{pH} 7.4$ containing $0.3 \%(\mathrm{w} / \mathrm{v})$ of sodium dodecyl sulfate $(\mathrm{SDS}))$ and incubated for $3 \mathrm{~h}$. Afterwards, a $\mathrm{NaCl}$ solution $(20 \mu \mathrm{L} ; 0.45 \mathrm{M})$ was added every $60 \mathrm{~min}$ to the AuNR suspension. This procedure was repeated 3 times and the suspension kept overnight under gentle shaking. Finally, the AuNR suspension was centrifuged at $9000 \mathrm{~g}$, the supernatant was collected and the pellet was resuspended in $10 \mathrm{mM}$ phosphate buffer containing $30 \mathrm{mM} \mathrm{NaCl}$. The amount of ssDNAs immobilized on the surface was determined indirectly by measuring absorbance at $260 \mathrm{~nm}$ in the supernatant. The ssDNA-AuNRs were stored at $4^{\circ} \mathrm{C}$ before use. 
Preparation of micro-RNAs conjugated with ssDNA. miR-ssDNA conjugates were prepared using $\mathrm{N}$-[ $\gamma$-maleimidobutyryloxy $]$ sulfosuccinimide ester (sulfo-GMBS, Thermo Scientific) as linker. miR-155 or miR-302a (60 $\mu \mathrm{L}$ at $100 \mu \mathrm{M}$ in PBS pH 8.0) were reacted with sulfo-GMBS in a 100-fold molar ratio for $30 \mathrm{~min}$ at room temperature. The excess of linker was removed by ultrafiltration with Nanosep $30 \mathrm{kDa}$ (Pall Corporation). The buffer was exchanged by PBS pH 7.0 and the purified miR $(60 \mu \mathrm{L} ; 100 \mu \mathrm{M}$ in PBS pH 7.0) was reacted with thiolated DNA $(60 \mu \mathrm{L} ; 200 \mu \mathrm{M}$ in PBS pH 7.0) in a final volume of $200 \mu \mathrm{L}$ of PBS for $2 \mathrm{~h}$ at room temperature. Before conjugation DNA strands were reduced with 100fold excess of TCEP for $1 \mathrm{~h}$ at $37{ }^{\circ} \mathrm{C}$. DNA strands were complementary to the strands immobilized on the AuNR surface (A:5'-HS-C6-TATACGAAGTTATAAAAAAAAAA or B: 5'-HS-C6-TGCCCTGGACCCGGAC). The products of miR and ssDNA conjugation were then separated in a Shimadzu-LC-20AD system using a $4.6 \times 250 \mathrm{~mm}$ XBridge C18 column packed with $3.5 \mu \mathrm{m}$ particles, average pore diameter $130 \AA$ (Waters).The mobile phases were as follows: 0.1 M TEAA pH 7.0 (A) and acetonitrile (B). The gradient started in $14 \%$ of $\mathrm{B}$ to $19 \%$ of $\mathrm{B}$ in $23 \mathrm{~min}$. The flow rate was $0.55 \mathrm{~mL} / \mathrm{min}$. The acetonitrile present in the fraction containing the miR-ssDNA conjugate was removed in a rotary evaporator. The final volume was aliquoted and stored at $-20^{\circ} \mathrm{C}$.

Characterization of miR conjugated with ssDNA by non-denaturing PAGE. The reaction mixture obtained after reacting miR-155 or miR-302a with ssDNA and the fractions obtained after HPLC purification of the reaction mixture were analysed by gel electrophoresis. Reaction mixture $(15 \mu \mathrm{L})$ and reaction mixture fractions obtained after HPLC purification $(15 \mu \mathrm{L})$ were mixed with glycerol $\left(5 \mu \mathrm{L}\right.$; glycerol in $50 \% \mathrm{v} / \mathrm{v}$ of $\mathrm{H}_{2} \mathrm{O}$ ), loaded in a 
polyacrylamide gel $(12 \%, \mathrm{w} / \mathrm{v})$ and run for $45 \mathrm{~min}$ in $0.5 \times \mathrm{TBE}$ at $140 \mathrm{~V}$. The gel was stained with SyBr Gold (1:5000 in $1 \times \mathrm{TBE})$ for $10 \mathrm{~min}$ and imaged in a UV transilluminator (Molecular Imager Gel DOC, Biorad).

Labelling of ssDNA-AuNR with TRITC. Thiol-PEG-amine 1 kDa (Creative PEGworks, 20 nmol) was reacted with TRITC $(20 \mathrm{nmol})$ in $1 \mathrm{~mL}$ of $10 \mathrm{mM}$ carbonate buffer at $\mathrm{pH} 9.0$ for 2 $\mathrm{h}$ at room temperature. Then ssDNA-AuNR $(500 \mu \mathrm{L}, 0.5 \mathrm{nM})$ were incubated overnight with thiol-PEG-TRITC in a molar ratio of 1:1000. The excess of fluorophore was removed in two steps of centrifugation at $9000 \mathrm{~g}$. The supernatants were then quantified for the presence of TRITC by fluorescence spectroscopy. On average, 540 fluorophores were immobilized on AuNRs.

Immobilization of miR-ssDNA conjugates in AuNRs. For the hybridization of complementary oligonucleotide strands conjugated with miR, a suspension of AuNR-ssDNA (0.5 nM) was incubated with DNA-miR conjugates $(400 \mathrm{nM})$ for $1 \mathrm{~h}$ at $37^{\circ} \mathrm{C}$ and then the temperature was slowly decreased to $25^{\circ} \mathrm{C}$. The excess of miR-DNA conjugate was removed by centrifugation. The amount of miR-ssDNA immobilized on the AuNRs was determined indirectly by measuring the concentration in the supernatant. For that, the supernatant was collected and incubated with SyBr Gold (diluted 1:10000). The fluorescence was measured in a Synergy HT microplate reader (excitation $495 \mathrm{~nm}$, emission $537 \mathrm{~nm}$ ) and the concentration was extrapolated from a calibration curve. 
Backfill with thiol-PEG. After conjugation with miR-ssDNA conjugates, the surface of AuNRs was backfilled with thiolated PEG (2 kDa). Briefly, a suspension of AuNR-DNA$\operatorname{miR}(500 \mu \mathrm{L}, 0.5 \mathrm{nM})$ was incubated with thiol-PEG at $25 \mu \mathrm{M}$ corresponding to a ratio of 1:50000 between AuNR and thiol-PEG. The reaction proceeded for $5 \mathrm{~h}$ at room temperature under orbital agitation. Then, the suspension was centrifuged (9000 g, $30 \mathrm{~min}$ ) and resuspended in $10 \mathrm{mM}$ phosphate $\mathrm{pH} 7.4$ with $30 \mathrm{mM} \mathrm{NaCl}$. The suspension was stored at $4^{\circ}$ C.

Cell culture. HEK-293T transfected with a reporter vector were kindly offered by Dr. Ricardo Neves. The vector was offered by Dr. Irvin Chen (David Geffen School of Medicine, University of California at Los Angeles). The reporter vector encodes EGFP conjugated to the targets of miR-302a and miR-302d, and mCherry conjugated to the targets of miR-142$3 p$, miR-155 and miR-223 $3^{25}$. Cells were cultured in T-75 culture flasks at $37{ }^{\circ} \mathrm{C}$ in a humidified atmosphere of $5 \% \mathrm{CO}_{2}$ in DMEM cell culture media containing $10 \% \mathrm{FBS}$ and $0.5 \%$ penicillin-streptomycin. Cells were grown to $80-90 \%$ confluency before splitting and re-seeding $24 \mathrm{~h}$ before each experiment. OECs cells were differentiated from $\mathrm{CD}_{3} 4^{+}$cells collected from umbilical cord blood mononuclear cells, as previously described. ${ }^{50}$

Cytotoxicity of miR-dsDNA-AuNR and CM. To assess the cytotoxicity of AuNRs, HEK293 T cells or OECs were seeded on a 96 well plate $\left(12 \times 10^{3}\right.$ cells/well), left to adhere for 24 $\mathrm{h}$ and then incubated with $\mathrm{dsDNA}_{51.7}$-AuNR $\left(50 \mu \mathrm{g} \mathrm{mL}^{-1}\right)$ with or without $\mathrm{CM}(2.5,5$ or 10 $\mu \mathrm{M}$ ) for $4 \mathrm{~h}$ in serum-free medium (DMEM for HEK-293T; EGM-2 for OECs). After incubation, cells were washed with PBS to remove non-internalized AuNRs and new medium was added (DMEM supplemented with 10\% FBS for HEK-293T; EGM-2 containing FBS for 
OECs). In some conditions, after incubation with AuNRs, cells were washed and irradiated with a $780 \mathrm{~nm}$ laser at $1.25 \mathrm{Wcm}^{-2}$ for $2 \mathrm{~min}$. After $2 \mathrm{~h}$ in the incubator at $37^{\circ} \mathrm{C}$, a subset of samples received a second laser stimulus for $2 \mathrm{~min}$ at $2 \mathrm{Wcm}^{-2}$. Then cells were left in the incubator for $24 \mathrm{~h}$ and ATP production was measured by a Celltiter-Glo Luminescent Cell Viability Assay (Promega) according to the manufacturer's instructions.

Cellular transfection with miRNAs and ssDNA-miRNAs. The ability of miR-155 and miR-302a to induce the knockdown of mCherry and EGFP respectively, was evaluated via transfection with lipofectamine RNAimax. HEK-293-T cells were seeded in a collagen coated 96 well plate (6500 cells/well) in DMEM (10\% FBS, without antibiotics) $24 \mathrm{~h}$ before transfection. MiR-155, miR-302a, ssDNA-miR-155 and ssDNA-miR-302a (35 $\mu \mathrm{L}$, concentrations ranging from 0.05 to $5 \mathrm{nM}$ ) were complexed for 20 min with lipofectamine RNAimax diluted in DMEM $(0.7 \mu \mathrm{L}$ of RNAimax in $35 \mu \mathrm{L}$ of DMEM). Then, each of the complexes was added to cells (20 $\mu \mathrm{L} /$ well) and incubated for $4 \mathrm{~h}$ or $24 \mathrm{~h}$. Finally, cells were washed, new culture medium was added and cell fluorescence was monitored in a highcontent fluorescence microscope (IN Cell 2200, GE Healthcare) each 12 h during 3 days.

The biological effect of miR-155 and miR-302a was also evaluated in OECs. OECs were seeded in a 96 well plate (10000 cells/well), left to adhere for $24 \mathrm{~h}$ and then transfected with miR-155 and/or miR-302a or scramble (50 nM) using lipofectamine RNAimax (Invitrogen) for $48 \mathrm{~h}$. The complex was prepared in EMB-2 $(10 \mu \mathrm{L})$ and added to cells on $90 \mu \mathrm{L}$ of gentamycin-free EGM-2. 
Activity of DNA-miR conjugates released from AuNRs. The activity of miR-155 and miR302a released from AuNR surface after irradiation was evaluated in reporter HEK-293T cells seeded in a 96 well plate $(6500$ cells/well). In order to study the laser induced release and activity of miR-DNA conjugates, we used AuNRs hybridized with: (i) miR-155 conjugated with ssDNA with a melting temperature of $51.7^{\circ} \mathrm{C}$ and (ii) miR-302a conjugated with ssDNA with a melting temperature of $68.9^{\circ} \mathrm{C}$. Each suspension of miR-dsDNA-AuNR was irradiated and immediately centrifuged. Then the supernatant was complexed for 20 min with lipofectamine RNAimax (35 $\mu \mathrm{L}$ of supernatant complexed with $35 \mu \mathrm{L}$ of RNAimax diluted 1:50 in DMEM) and $20 \mu \mathrm{L}$ of this mixture was added to each well containing $100 \mu \mathrm{L}$ of DMEM with $10 \%$ FBS. After incubation, cells were kept in DMEM $(10 \%$ FBS, $0.3 \mu \mathrm{g} / \mathrm{mL}$ of Hoechst) and mCherry/EGFP fluorescence was monitored by a high-content fluorescence microscope (IN Cell 2200, GE Healthcare) during 3 days (intervals of $12 \mathrm{~h}$ ). For quantification of fluorescence, cells were segmented using IN Cell analyzer software and the mean intensity levels of mCherry and EGFP fluorescence were calculated for each segmented cell. Finally, the fluorescence of the background was subtracted in each case.

Intracellular trafficking of miR-dsDNA-AuNR-TRITC by confocal microscopy. Cells were seeded in an IBIDI 15 well slide ( $80 \%$ confluency), left to adhere for $24 \mathrm{~h}$ and then incubated with miR-155-dsDNA 51.7 -AuNR-TRITC $\left(50 \mu \mathrm{gmL}^{-1}\right)$ for $4 \mathrm{~h}$ with or without CM (5 or $10 \mu \mathrm{M})$ in DMEM $(0.5 \%$ PenStrep, without FBS). After incubation, cells were washed with medium to remove non-internalized AuNRs. Then, the cells were incubated with Lysotracker ${ }^{\circledR}$ Green $(100 \mathrm{nM})$ for $30 \mathrm{~min}$ to stain the endosomes and with Hoechst 33342 $\left(0.3 \mu \mathrm{gmL}^{-1}\right)$ to stain the nuclei. Cells were then observed under a confocal microscope. Images were acquired on a Zeiss LSM 710 confocal microscope (Carl Zeiss, Jena, Germany) using a $40 \times$ objective/ 1.4 numerical aperture oil PlanApochromat immersion lens. 
Lysotraker Green was detected using the $488 \mathrm{~nm}$ laser line of an Ar laser (25 mW nominal output) and an LP 505 filter. TRITC was detected using a $561 \mathrm{~nm}$ HeNe laser (1 mW) and an LP 560 filter. The pinhole aperture was set to 1 Airy unit. Image acquisition was performed using the Zen Black 2012 software. Images were analyzed in ImageJ and the colocalization was determined by calculating the Manders' colocalization coefficient between AuNRTRITC and Lysotracker green.

\section{Intracellular trafficking of miR-dsDNA-AuNR by transmission electron microscopy}

(TEM). Cells were seeded in a 24 well plate, left to adhere for $24 \mathrm{~h}$ to $90 \%$ of confluency and then incubated with miR-155-dsDNA $51.7-\operatorname{AuNR}\left(50 \mu \mathrm{gmL}^{-1}\right)$ and $\mathrm{CM}(10 \mu \mathrm{M})$. After $4 \mathrm{~h}$ incubation, the medium was replaced and cells were irradiated with a fibercoupled Roithner laser $(780 \mathrm{~nm})$ at $1.25 \mathrm{~W} \mathrm{~cm}^{-2}$ for $2 \mathrm{~min}$. The culture medium was removed, cells were washed with PBS and then fixed for $1 \mathrm{~h}$ with $2.5 \%$ glutaraldehyde and $2.0 \%$ paraformaldehyde in $0.1 \mathrm{M}$ sodium cacodylate buffer $\mathrm{pH} 7.4$, containing sucrose $(0.1 \mathrm{M})$, $\mathrm{KCl}(50 \mathrm{mM}), \mathrm{MgCl}(2.5 \mathrm{mM})$ and $\mathrm{CaCl}(1.25 \mathrm{mM})$. Cells were post-fixed for $1 \mathrm{~h}$ in a 2\% osmium tetroxide solution containing $0.8 \%$ potassium ferrocyanide in $0.1 \mathrm{M}$ sodium cacodylate buffer. The samples were washed with distilled water and soaked overnight in aqueous $1 \%$ uranyl acetate at $4{ }^{\circ} \mathrm{C}$. Then the samples were dehydrated in graded alcohols and embedded in resin. TEM images were acquired with a Tecnai Spirit microscope (EM) (FEI, Eindhoven, The Netherlands) equipped with a LaB6 cathode. Images were acquired with a $1376 \times 1024$ pixel CCD camera (FEI, Eindhoven, The Netherlands), with a magnification between $20000 \times$ and $80000 \times$. In each image, the number of AuNRs in cell compartments (endolysosomal compartments and cytosol) was counted and divided by the total number of AuNRs per image to obtain percentage of AuNRs per compartment. 
Light-induced release of DNA-miR conjugates in reporter HEK-293T. HEK-293T cells

Light-induced release of DNA-miR conjugates in OECs. OECs were seeded in a 96 well plate (10000 cells/well), left to adhere for $24 \mathrm{~h}$ and then incubated with a mixture of miR155-dsDNA 51.7 -AuNRs $\left(25 \mu \mathrm{gmL}^{-1}\right)$ with miR-302a-dsDNA 68.9 -AuNRs $\left(25 \mu \mathrm{gmL}^{-1}\right)$, (corresponding to $20.2 \mathrm{nM}$ of miR-155 and $19.5 \mathrm{nM}$ of miR-302a). The suspension of miRdsDNA-AuNRs was prepared in serum-free EGM-2. Before adding to cells, the suspension was mixed with CM peptide (final concentration of $5 \mu \mathrm{M}$ ). After $4 \mathrm{~h}$ incubation, the medium 
was replaced for EGM-2 and cells were irradiated with a fibercoupled laser (780 nm) at 1.25 $\mathrm{Wcm}^{-2}$ for $2 \mathrm{~min}$ and $2 \mathrm{~h}$ later cells were subjected to a second stimulus of $2 \mathrm{Wcm}^{-2}$ for $2 \mathrm{~min}$.

Proliferation and survival assays. For the proliferation studies, $48 \mathrm{~h}$ after the AuNR incubation, cells were incubated with Hoechst $33342\left(1 \mu \mathrm{g} \mathrm{mL} \mathrm{L}^{-1}\right)$ and nuclei were counted in a high-content fluorescence microscope (IN Cell 2200, GE Healthcare). The same cells were then cultured for additional $48 \mathrm{~h}$ in ischemic conditions $\left(0.1 \% \mathrm{O}_{2}\right.$ and EBM-2 medium, in plates covered with Breathe-Easy ${ }^{\circledR}$ sealing membranes, Sigma) to quantify their survival. At the end of incubation cells were incubated with Hoechst $33342\left(1 \mu \mathrm{gmL}^{-1}\right)$ and nuclei were counted in a high-content fluorescence microscope. Cells treated with VEGF $\left(50 \mathrm{ngmL}^{-1}\right)$ were used as positive control of the experiment.

Sequential release of DNA-miR conjugates in OECs. OECs seeded in a 96 well plate (5000/well) were incubated with miR-dsDNA-AuNRs as described previously (see section "Light-induced release of DNA-miR conjugates in OECs") and then irradiated with a single stimulus of $2 \mathrm{Wcm}^{-2}$ for 2 min to induce release of both miRNAs, or with two irradiation stimuli of $1.25 \mathrm{Wcm}^{-2}$ and $2 \mathrm{Wcm}^{-2}$ with $24 \mathrm{~h}$ interval between them to induce sequential release of miRNAs. After irradiation, cells were cultured for additional $48 \mathrm{~h}$ in ischemic conditions $\left(0.1 \% \mathrm{O}_{2}\right.$ and EBM-2 medium, in plates covered with Breathe-Easy ${ }^{\circledR}$ sealing membranes, Sigma). After incubation, cells were stained with Hoechst $33342\left(1 \mu \mathrm{gmL}^{-1}\right)$ and nuclei were counted in a high-content fluorescence for quantification of cell survival. 
Quantification of miRNAs by qRT-PCR. HEK-293T cells were seeded in a 24 well plate $\left(1 \times 10^{5}\right.$ cells/well $)$ and left to adhere for $24 \mathrm{~h}$. Cells were incubated for $4 \mathrm{~h}$ with a mixture of miR155-dsDNA $51.7-A u N R\left(25 \mu \mathrm{gmL}^{-1}\right)$ and miR302a-dsDNA $68.9-\mathrm{AuNR}\left(25 \mu \mathrm{g} \mathrm{mL}^{-1}\right)$ in the presence of CM $(10 \mu \mathrm{M})$ in DMEM without FBS. Then cells were washed twice with PBS and lysed with RLT buffer (Qiagen). Subsequently, miRNAs were isolated using miRCURY RNA isolation kit (Exiqon), followed by cDNA preparation from 10 ng total RNA using miRCURY LNA ${ }^{\mathrm{TM}}$ Universal RT microRNA (Exiqon). Quantitative PCR (qPCR) was performed using NZYSpeedy qPCR Green, (NZYtech) and the detection was carried out in a 7500 Fast Real-Time PCR System (Applied Biosystems). A calibration curve was done using known concentrations of each miRNA. U6 was used as an endogenous standard. Hsa-miR LNA $^{\text {TM }}$ PCR primer sets (Exiqon) specific for each miR-155-5p and miR-302a-3p were used for the quantification.

Gene analysis. OECs were transfected with miR-155 and miR-302a, as previously described. After $48 \mathrm{~h}$ transfection, cells were lysed with RLT buffer and total RNA was isolated using RNeasy Micro Kit (Qiagen). DELTAgene assays (FlexSix - Fluidigm) were designed. The pre-amplification process was performed for 14 cycles. The oligos were synthesized by Sigma (Table S2) and dissolved at a concentration of $100 \mu \mathrm{M}$ in water. For each assay a Primer Pair Mix was prepared containing $50 \mu \mathrm{M}$ Forward Primer and $50 \mu \mathrm{M}$ Reverse Primer. In order to prepare $10 \times$ Pre-amplification Primer Mix (500 nM each primer), each Primer Pair Mixes (10 $\mu \mathrm{L}, 50 \mu \mathrm{M}$ each primer) was mixed with $40 \mu \mathrm{L}$ buffer consisting of $10 \mathrm{mM}$ Tris-HCl, pH 8.0; $0.1 \mathrm{mM}$ EDTA; 0.25\% Tween-20. In order to prepare $10 \times$ Assay $(5 \mu \mathrm{M}$ each primer) each Primer Pair Mix was diluted by mixing $10 \mu \mathrm{L}$ Primer Pair Mix $(50 \mu \mathrm{M}$ each primer) with $90 \mu \mathrm{L}$ buffer consisting of $10 \mathrm{mM}$ Tris-HCl, $\mathrm{pH} 8.0 ; 0.1 \mathrm{mM}$ EDTA; $0.25 \%$ Tween-20. A pre-mix containing cDNA and primers was done and treatment with 
exonuclease I was performed to remove non-hybridized primers. The Fluidigm ${ }^{\circledR}$ FLEXsix ${ }^{\mathrm{TM}}$ Gene expression IFC was used with EvaGreen chemistry. After a prime of the chip, a 10x assay mix and sample mix were pipetted into the inlets. The chip was loaded and data was collected using the BioMark $\mathrm{HD}^{\mathrm{TM}}$. Data was analyzed using Fluidigm ${ }^{\circledR}$ Real Time PCR Analysis v2.1 software.

\section{In vivo experiments}

Preparation of cells for transplantation. OECs were seeded in gelatin coated T75 flasks $\left(2.8 \times 10^{6}\right.$ cells/flask $)$ and left to adhere overnight. Then cells were incubated with different combinations of AuNR formulations (A: $25 \mu \mathrm{g} / \mathrm{mL}$ of miR155-dsDNA $51.7-\mathrm{AuNR}+25$ $\mu \mathrm{g} / \mathrm{mL}$ of miR302a-dsDNA 68.9 -AuNR, corresponding to $20.2 \mathrm{nM}$ of miR-155 and $19.5 \mathrm{nM}$ of miR302a; B: $25 \mu \mathrm{g} / \mathrm{mL}$ miR302a-dsDNA $51.7-\mathrm{AuNR}+25 \mu \mathrm{g} / \mathrm{mL}$ miR155-dsDNA $68.9-\mathrm{AuNR}$, corresponding to $20.2 \mathrm{nM}$ of miR-155 and $19.5 \mathrm{nM}$ of miR302a) for $4 \mathrm{~h}$ in EGM-2 without FBS and with CM $(5 \mu \mathrm{M})$. After incubation, cells were washed with PBS, trypsinized, centrifuged and resuspended in $1 \mathrm{~mL}$ of EGM-2. Then cells were counted and the final concentration was adjusted to $1 \times 10^{6}$ cells $/ \mathrm{mL}$. Cells were kept in ice until transplantation. Immediately before transplantation, aliquots containing $3.5 \times 10^{5}$ cells were centrifuged for 3 min at $250 \mathrm{~g}$ and resuspended in PBS $(50 \mu \mathrm{L})$.

In vivo wound model and cell transplantation. Animal protocol was approved by the Ethics Committee of the Faculty of Medicine of the University of Coimbra (ORBEA_159_2017/05052017). Male nude mice (6 weeks) were purchased from Charles River (Wilmington, MA, USA). The animals were anesthetized, the dorsolumbar skin was 
disinfected and two $6 \mathrm{~mm}$-diameter dorsal full-thickness excisional wounds were created with a sterile biopsy punch in each animal. Then, cells $\left(3.5 \times 10^{5}\right.$ cells in $50 \mu \mathrm{L}$ of PBS $)$ were injected subcutaneously in a single spot between 5 to $10 \mathrm{~mm}$ from the wound. After transplantation, the injection spot was irradiated for $2 \mathrm{~min}$ at $1.25 \mathrm{Wcm}^{-2}$. Twenty four hours after the first injection, the animals were irradiated again for 2 min at $2 \mathrm{Wcm}^{-2}$. The animals were maintained in individual cages with food and water ad libitum and in a temperature and humidity-controlled environment. The rate of wound closure was determined over ten days. At the end of the study, animals were sacrificed by cervical dislocation.

Tissue processing. At day 5 or day 15 post-wounding, mice were sacrificed and skin from wound area and injection site were excised and fixed in $10 \%$ neutral buffered formalin or stored at $-80^{\circ} \mathrm{C}$. The fixed samples were processed for paraffin embedding.

Quantification of human DNA in mouse skin samples by RT-PCR. Skin samples from the injection site (approximately $50 \mathrm{mg}$ ) were homogenized with steel beads in $1 \mathrm{~mL}$ of TRIZOL using a TissueLyser (Qiagen, Netherlands) operated at $30 \mathrm{~Hz}$ in two cycles of $2 \mathrm{~min}$. DNA was extracted following the manufacturer's instructions and the final concentration was determined in Nanodrop. A pre-amplification was performed using $100 \mathrm{ng}$ of DNA and PreAmp Master mix (Fluidigm) $\left(15\right.$ cycles: $\left.95^{\circ} \mathrm{C}-15 \mathrm{sec}, 67^{\circ} \mathrm{C}-4 \mathrm{~min}\right)$. Quantitative PCR (qPCR) was performed using NZYSpeedy qPCR Green, (NZYtech) and the detection was carried out in a 7500 Fast Real-Time PCR System (Applied Biosystems). The primers used for specific amplification of human DNA are presented in Table S2. A calibration curve was generated using serial dilutions of human DNA isolated from OECs into mouse DNA. 
Immunohistochemistry. Mouse skin sections ( $3 \mu \mathrm{m}$ thickness) were deparaffinized and rehydrated, after which antigen retrieval was performed at $97^{\circ} \mathrm{C}$ for $20 \mathrm{~min}$ in citrate buffer $\mathrm{pH}$ 6.0. Next, the sections were blocked for $1 \mathrm{~h}$ in $5 \%$ BSA and for $30 \mathrm{~min}$ at room temperature with primary antibody anti-human CD31 (1:30, clone JC70A, DAKO). Then, the sections were incubated overnight at $4^{\circ} \mathrm{C}$ with primary antibodies mouse anti-human $\mathrm{CD} 31$ (1:30, clone JC70A, DAKO) and rabbit anti-mouse/human CD31 (1:50, Abcam 28364). Finally, the samples were stained with secondary antibody Alexa Fluor 488 goat anti-mouse (1:800, Invitrogen) for $1 \mathrm{~h}$ at room temperature, followed by $1 \mathrm{~h}$ incubation with secondary antibody Cy3 goat anti-rabbit (1:800, Jackson Laboratory) and then stained with DAPI. Images were acquired on a Zeiss LSM 710 confocal microscope (Carl Zeiss, Jena, Germany) using a $40 \times$ objective/ 1.4 numerical aperture oil Plan Apochromat immersion lens.

Histological analysis. Samples embedded in paraffin were sectioned at $4 \mu \mathrm{m}$, and stained with hematoxylin and eosin. Histological analysis was performed by a pathologist. Granulation-tissue formation and inflammation at the wound gap, were analyzed using NDP.view2 software coupled to Nanozoomer SQ slide scanner (Hamamatsu).

\section{REFERENCES}

1. Sanganalmath, S. K.; Bolli, R., Cell therapy for heart failure: a comprehensive overview of experimental and clinical studies, current challenges, and future directions. Circ. Res. 2013, 113, 810-34.

2. Raval, Z.; Losordo, D. W., Cell therapy of peripheral arterial disease: from experimental findings to clinical trials. Circ. Res. 2013, 112, 1288-302.

3. Asahara, T.; Kawamoto, A.; Masuda, H., Concise review: Circulating endothelial progenitor cells for vascular medicine. Stem Cells 2011, 29, 1650-5. 
4. Fadini, G. P.; Losordo, D.; Dimmeler, S., Critical Reevaluation of Endothelial Progenitor Cell Phenotypes for Therapeutic and Diagnostic Use. Circ. Res. 2012, 110, 624637.

5. $\quad$ Kinoshita, M.; Fujita, Y.; Katayama, M.; Baba, R.; Shibakawa, M.; Yoshikawa, K.; Katakami, N.; Furukawa, Y.; Tsukie, T.; Nagano, T.; Kurimoto, Y.; Yamasaki, K.; Handa, N.; Okada, Y.; Kuronaka, K.; Nagata, Y.; Matsubara, Y.; Fukushima, M.; Asahara, T.; Kawamoto, A., Long-term clinical outcome after intramuscular transplantation of granulocyte colony stimulating factor-mobilized CD34 positive cells in patients with critical limb ischemia. Atherosclerosis 2012, 224, 440-445.

6. Kawamoto, A.; Losordo, D. W., Endothelial progenitor cells for cardiovascular regeneration. Trends Cardiovasc. Med. 2008, 18, 33-7.

7. Fuchs, S.; Motta, A.; Migliaresi, C.; Kirkpatrick, C. J., Outgrowth endothelial cells isolated and expanded from human peripheral blood progenitor cells as a potential source of autologous cells for endothelialization of silk fibroin biomaterials. Biomaterials 2006, 27, 5399-5408.

8. Bartel, D. P., MicroRNAs: Genomics, Biogenesis, Mechanism, and Function. Cell 2004, 116, 281-297.

9. Suarez, Y.; Sessa, W. C., MicroRNAs As Novel Regulators of Angiogenesis. Circ. Res. 2009, 104, 442-454.

10. Hua, Z.; Lv, Q.; Ye, W.; Wong, C.-K. A.; Cai, G.; Gu, D.; Ji, Y.; Zhao, C.; Wang, J.; Yang, B. B.; Zhang, Y., MiRNA-Directed Regulation of VEGF and Other Angiogenic Factors under Hypoxia. PLoS One 2006, 1, e116.

11. Greer Card, D. A.; Hebbar, P. B.; Li, L.; Trotter, K. W.; Komatsu, Y.; Mishina, Y.; Archer, T. K., Oct4/Sox2-Regulated miR-302 Targets Cyclin D1 in Human Embryonic Stem Cells. Mol. Cell. Biol. 2008, 28, 6426-6438.

12. Pulkkinen, K. H.; Ylä-Herttuala, S.; Levonen, A.-L., Heme oxygenase 1 is induced by miR-155 via reduced BACH1 translation in endothelial cells. Free Radical Biol. Med. 2011, $51,2124-2131$.

13. Tang, Y. L.; Tang, Y.; Zhang, Y. C.; Qian, K.; Shen, L.; Phillips, M. I., Improved Graft Mesenchymal Stem Cell Survival in Ischemic Heart With a Hypoxia-Regulated Heme Oxygenase-1 Vector. J. Am. Coll. Cardiol. 2005, 46, 1339-1350.

14. Wang, H.; Agarwal, P.; Zhao, S.; Yu, J.; Lu, X.; He, X., A Near-Infrared LaserActivated "Nanobomb" for Breaking the Barriers to MicroRNA Delivery. Adv. Mater. 2016, 28, 347-355.

15. Huschka, R.; Barhoumi, A.; Liu, Q.; Roth, J. A.; Ji, L.; Halas, N. J., Gene Silencing by Gold Nanoshell-Mediated Delivery and Laser-Triggered Release of Antisense Oligonucleotide and siRNA. ACS Nano 2012, 6, 7681-7691.

16. Chang, Y.-T.; Liao, P.-Y.; Sheu, H.-S.; Tseng, Y.-J.; Cheng, F.-Y.; Yeh, C.-S., NearInfrared Light-Responsive Intracellular Drug and siRNA Release Using Au Nanoensembles with Oligonucleotide-Capped Silica Shell. Adv. Mater. 2012, 24, 3309-3314.

17. Yang, Y.; Liu, F.; Liu, X.; Xing, B., NIR light controlled photorelease of siRNA and its targeted intracellular delivery based on upconversion nanoparticles. Nanoscale 2013, 5, 231-238.

18. Braun, G. B.; Pallaoro, A.; Wu, G.; Missirlis, D.; Zasadzinski, J. A.; Tirrell, M.; Reich, N. O., Laser-Activated Gene Silencing via Gold Nanoshell-siRNA Conjugates. ACS Nano 2009, 3, 2007-2015.

19. Huschka, R.; Zuloaga, J.; Knight, M. W.; Brown, L. V.; Nordlander, P.; Halas, N. J., Light-Induced Release of DNA from Gold Nanoparticles: Nanoshells and Nanorods. J. Am. Chem. Soc. 2011, 133, 12247-12255. 
20. Ferrer-Miralles, N.; Vázquez, E.; Villaverde, A., Membrane-active peptides for nonviral gene therapy: making the safest easier. Trends in Biotechnol. 2008, 26, 267-275.

21. Maleki, H.; Rai, A.; Pinto, S.; Evangelista, M.; Cardoso, R. M.; Paulo, C.;

Carvalheiro, T.; Paiva, A.; Imani, M.; Simchi, A.; Duraes, L.; Portugal, A.; Ferreira, L., High

Antimicrobial Activity and Low Human Cell Cytotoxicity of Core-Shell Magnetic

Nanoparticles Functionalized with an Antimicrobial Peptide. ACS Appl. Mater. Interfaces 2016, $8,11366-78$.

22. Rai, A.; Pinto, S.; Velho, T. R.; Ferreira, A. F.; Moita, C.; Trivedi, U.; Evangelista, M.; Comune, M.; Rumbaugh, K. P.; Simoes, P. N.; Moita, L.; Ferreira, L., One-step synthesis of high-density peptide-conjugated gold nanoparticles with antimicrobial efficacy in a systemic infection model. Biomaterials 2016, 85, 99-110.

23. Hou, K. K.; Pan, H.; Ratner, L.; Schlesinger, P. H.; Wickline, S. A., Mechanisms of Nanoparticle-Mediated siRNA Transfection by Melittin-Derived Peptides. ACS Nano 2013, 7, 8605-8615.

24. Boeckle, S.; Fahrmeir, J.; Roedl, W.; Ogris, M.; Wagner, E., Melittin analogs with high lytic activity at endosomal $\mathrm{pH}$ enhance transfection with purified targeted PEI polyplexes. J. Controlled Release 2006, 112, 240-8.

25. Kamata, M.; Liang, M.; Liu, S.; Nagaoka, Y.; Chen, I. S. Y., Live Cell Monitoring of hiPSC Generation and Differentiation Using Differential Expression of Endogenous microRNAs. PLoS One 2010, 5, e11834.

26. Nikoobakht, B.; El-Sayed, M. A., Preparation and Growth Mechanism of Gold Nanorods (NRs) Using Seed-Mediated Growth Method. Chem. Mater. 2003, 15, 1957-1962.

27. Storhoff, J. J.; Elghanian, R.; Mirkin, C. A.; Letsinger, R. L., Sequence-Dependent Stability of DNA-Modified Gold Nanoparticles. Langmuir 2002, 18, 6666-6670.

28. Chiu, Y.-L.; Rana, T. M., siRNA function in RNAi: A chemical modification analysis. RNA 2003, 9, 1034-1048.

29. Fasoli, A.; Salomone, F.; Benedusi, M.; Boccardi, C.; Rispoli, G.; Beltram, F.; Cardarelli, F., Mechanistic Insight into CM18-Tat11 Peptide Membrane-Perturbing Action by Whole-Cell Patch-Clamp Recording. Molecules 2014, 19, 9228.

30. Salomone, F.; Cardarelli, F.; Di Luca, M.; Boccardi, C.; Nifosì, R.; Bardi, G.; Di Bari, L.; Serresi, M.; Beltram, F., A novel chimeric cell-penetrating peptide with membranedisruptive properties for efficient endosomal escape. J. Controlled Release 2012, 163, 293 303.

31. Ferre, R.; Melo, M. N.; Correia, A. D.; Feliu, L.; Bardaji, E.; Planas, M.; Castanho, M., Synergistic effects of the membrane actions of cecropin-melittin antimicrobial hybrid peptide BP100. Biophys. J. 2009, 96, 1815-27.

32. Krpetić, Ž.; Nativo, P.; Sée, V.; Prior, I. A.; Brust, M.; Volk, M., Inflicting Controlled Nonthermal Damage to Subcellular Structures by Laser-Activated Gold Nanoparticles. Nano Lett. 2010, 10, 4549-4554.

33. Rai, A.; Pinto, S.; Velho, T. R.; Ferreira, A. F.; Moita, C.; Trivedi, U.; Evangelista, M.; Comune, M.; Rumbaugh, K. P.; Simões, P. N.; Moita, L.; Ferreira, L., One-step synthesis of high-density peptide-conjugated gold nanoparticles with antimicrobial efficacy in a systemic infection model. Biomaterials 2016, 85, 99-110.

34. Rai, A.; Pinto, S.; Evangelista, M. B.; Gil, H.; Kallip, S.; Ferreira, M. G. S.; Ferreira, L., High-density antimicrobial peptide coating with broad activity and low cytotoxicity against human cells. Acta Biomater. 2016, 33 (Supplement C), 64-77.

35. Maity, S.; Wu, W.-C.; Xu, C.; Tracy, J. B.; Gundogdu, K.; Bochinski, J. R.; Clarke, L. I., Spatial temperature mapping within polymer nanocomposites undergoing ultrafast photothermal heating via gold nanorods. Nanoscale 2014, 6, 15236-15247. 
36. Wang, Y.; Baskerville, S.; Shenoy, A.; Babiarz, J. E.; Baehner, L.; Blelloch, R., Embryonic Stem Cell Specific MicroRNAs Regulate the G1/S Transition and Promote Rapid Proliferation. Nat. Genet. 2008, 40, 1478-1483.

37. Kikuchi, J.; Kinoshita, I.; Shimizu, Y.; Kikuchi, E.; Takeda, K.; Aburatani, H.; Oizumi, S.; Konishi, J.; Kaga, K.; Matsuno, Y.; Birrer, M. J.; Nishimura, M.; Dosaka-Akita, $\mathrm{H}$., Minichromosome maintenance (MCM) protein 4 as a marker for proliferation and its clinical and clinicopathological significance in non-small cell lung cancer. Lung Cancer 2011, 72, 229-237.

38. Chang, S.-H.; Hla, T., Gene regulation by RNA binding proteins and microRNAs in angiogenesis. Trends Mol. Med. 2011, 17, 650-658.

39. Gomes, R. S. M.; Neves, R. P. d.; Cochlin, L.; Lima, A.; Carvalho, R.; Korpisalo, P.; Dragneva, G.; Turunen, M.; Liimatainen, T.; Clarke, K.; Ylä-Herttuala, S.; Carr, C.; Ferreira, L., Efficient Pro-survival/angiogenic miRNA Delivery by an MRI-Detectable Nanomaterial. ACS Nano 2013, 7, 3362-3372.

40. Masotti, A.; Miller, M. R.; Celluzzi, A.; Rose, L.; Micciulla, F.; Hadoke, P. W. F.; Bellucci, S.; Caporali, A., Regulation of angiogenesis through the efficient delivery of microRNAs into endothelial cells using polyamine-coated carbon nanotubes. Nanomedicine 2016, 12, 1511-1522.

41. Lucas, T.; Schafer, F.; Muller, P.; Eming, S. A.; Heckel, A.; Dimmeler, S., Lightinducible antimiR-92a as a therapeutic strategy to promote skin repair in healing-impaired diabetic mice. Nat. Commun. 2017, 8, 15162.

42. Ramakrishnan, P.; Maclean, M.; MacGregor, S. J.; Anderson, J. G.; Grant, M. H., Cytotoxic responses to $405 \mathrm{~nm}$ light exposure in mammalian and bacterial cells: Involvement of reactive oxygen species. Toxicol. in Vitro 2016, 33 (Supplement C), 54-62.

43. Agostinis, P.; Berg, K.; Cengel, K. A.; Foster, T. H.; Girotti, A. W.; Gollnick, S. O.; Hahn, S. M.; Hamblin, M. R.; Juzeniene, A.; Kessel, D.; Korbelik, M.; Moan, J.; Mroz, P.; Nowis, D.; Piette, J.; Wilson, B. C.; Golab, J., Photodynamic therapy of cancer: An update. CA: Cancer J. Clin. 2011, 61, 250-281.

44. Weissleder, R., A clearer vision for in vivo imaging. Nat. Biotechnol. 2001, 19, 316.

45. Kasinski, A. L.; Kelnar, K.; Stahlhut, C.; Orellana, E.; Zhao, J.; Shimer, E.; Dysart, S.; Chen, X.; Bader, A. G.; Slack, F. J., A combinatorial microRNA therapeutics approach to suppressing non-small cell lung cancer. Oncogene 2015, 34, 3547-3555.

46. Torres, S.; Garcia-Palmero, I.; Bartolomé, R. A.; Fernandez-Aceñero, M. J.; Molina, E.; Calviño, E.; Segura, M. F.; Casal, J. I., Combined miRNA profiling and proteomics demonstrates that different miRNAs target a common set of proteins to promote colorectal cancer metastasis. J. Pathol. 2017, 242, 39-51.

47. Conde, J.; Oliva, N.; Atilano, M.; Song, H. S.; Artzi, N., Self-assembled RNA-triplehelix hydrogel scaffold for microRNA modulation in the tumour microenvironment. Nat. Mater. 2015, 15, 353.

48. Wijaya, A.; Schaffer, S. B.; Pallares, I. G.; Hamad-Schifferli, K., Selective Release of Multiple DNA Oligonucleotides from Gold Nanorods. ACS Nano 2009, 3, 80-86.

49. Wijaya, A.; Hamad-Schifferli, K., Ligand Customization and DNA Functionalization of Gold Nanorods via Round-Trip Phase Transfer Ligand Exchange. Langmuir 2008, 24, 9966-9969.

50. Pedroso, D. C. S.; Tellechea, A.; Moura, L.; Fidalgo-Carvalho, I.; Duarte, J.; Carvalho, E.; Ferreira, L., Improved Survival, Vascular Differentiation and Wound Healing Potential of Stem Cells Co-Cultured with Endothelial Cells. PLoS One 2011, 6, e16114. 


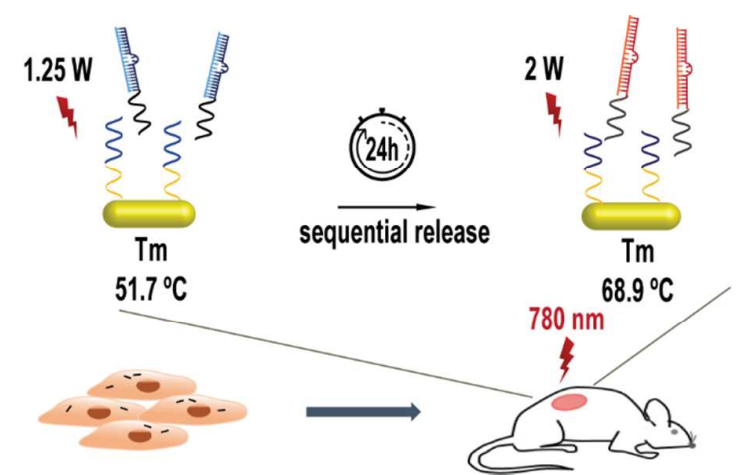

Table of Contents

ACS Paragon Plus Environment 